\title{
Analysis and Optimization of Process Parameters in Abrasive Waterjet Contour Cutting of AISI 304L
}

\author{
Jennifer Milaor Llanto*(D), Ana Vafadar (D), Muhammad Aamir (D) and Majid Tolouei-Rad \\ School of Engineering, Edith Cowan University, Joondalup, WA 6027, Australia; \\ a.vafadarshamasbi@ecu.edu.au (A.V.); m.aamir@ecu.edu.au (M.A.); m.rad@ecu.edu.au (M.T.-R.) \\ * Correspondence: j.llanto@ecu.edu.au; Tel.: +61-404-138-991
}

check for

updates

Citation: Llanto, J.M.; Vafadar, A.; Aamir, M.; Tolouei-Rad, M. Analysis and Optimization of Process Parameters in Abrasive Waterjet Contour Cutting of AISI 304L. Metals 2021, 11, 1362. https://doi.org/ 10.3390/met11091362

Academic Editors:

Tadeusz Mikolajczyk, Danil

Yurievich Pimenov and Munish Kumar Gupta

Received: 30 July 2021

Accepted: 27 August 2021

Published: 30 August 2021

Publisher's Note: MDPI stays neutral with regard to jurisdictional claims in published maps and institutional affiliations.

Copyright: (c) 2021 by the authors. Licensee MDPI, Basel, Switzerland. This article is an open access article distributed under the terms and conditions of the Creative Commons Attribution (CC BY) license (https:// creativecommons.org/licenses/by/ $4.0 /)$.

\begin{abstract}
Abrasive waterjet machining is applied in various industries for contour cutting of heatsensitive and difficult-to-cut materials like austenitic stainless steel $304 \mathrm{~L}$, with the goal of ensuring high surface integrity and efficiency. In alignment with this manufacturing aspiration, experimental analysis and optimization were carried out on abrasive waterjet machining of austenitic stainless steel 304L with the objectives of minimizing surface roughness and maximizing material removal rate. In this machining process, process parameters are critical factors influencing contour cutting performance. Accordingly, Taguchi's S/N ratio method has been used in this study for the optimization of process parameters. Further in this work, the impacts of input parameters are investigated, including waterjet pressure, abrasive mass flow rate, traverse speed and material thickness on material removal rate and surface roughness. The study reveals that an increasing level of waterjet pressure and abrasive mass flow rate achieved better surface integrity and higher material removal values. The average $\mathrm{S} / \mathrm{N}$ ratio results indicate an optimum value of waterjet pressure at $300 \mathrm{MPa}$ and abrasive mass flow rate of $500 \mathrm{~g} / \mathrm{min}$ achieved minimum surface roughness and maximum material removal rate. It was also found that an optimized value of a traverse speed at $90 \mathrm{~mm} / \mathrm{min}$ generates the lowest surface roughness and $150 \mathrm{~mm} / \mathrm{min}$ produces the highest rate of material removed. Moreover, analysis of variance in the study showed that material thickness was the most influencing parameter on surface roughness and material removal rate, with a percentage contribution ranging $90.72-97.74 \%$ and $65.55-78.17 \%$, respectively.
\end{abstract}

Keywords: abrasive waterjet machining; metal contour cutting; surface roughness; material removal rate; Taguchi method; ANOVA

\section{Introduction}

Abrasive waterjet machining (AWJM) is a non-traditional cold processing technology used for material processing, with considerable advantages including the absence of heat affected zones, low tool wear, low reaction force, high flexibility, as well as broad application range [1]. In general, the AWJM system consists of four major elements: (1) a high pressure pump producing a flow of pressurized water; (2) an abrasive flow control systems and a cutting head that generates the abrasive water jet machining; (3) a computer-based controller that controls the activity of the cutting head motion; and (4) a water-filled tank that disseminates energy of the abrasive water jet upon completion of machining the workpiece [2]. The fundamental mechanism of abrasive waterjet cutting is material erosion through waterjet eroding, with force and disparity in the momentum of the abrasives colliding on the target material.

An AWJM nozzle system consists of an abrasive hopper and feeder, a water nozzle/orifice, a mixing/vacuum chamber, and a focusing tube or inserts. The abrasive particles are carried out from the plastic tube into the hopper, where they are released to the cutting head and extracted by a waterjet stream in the vacuum chamber. The high-pressure waterjet is then combined with abrasive particles and accelerated to produce the abrasive waterjet [3]. Figure 1 represents the scheme of abrasive waterjet nozzle and parameters. 


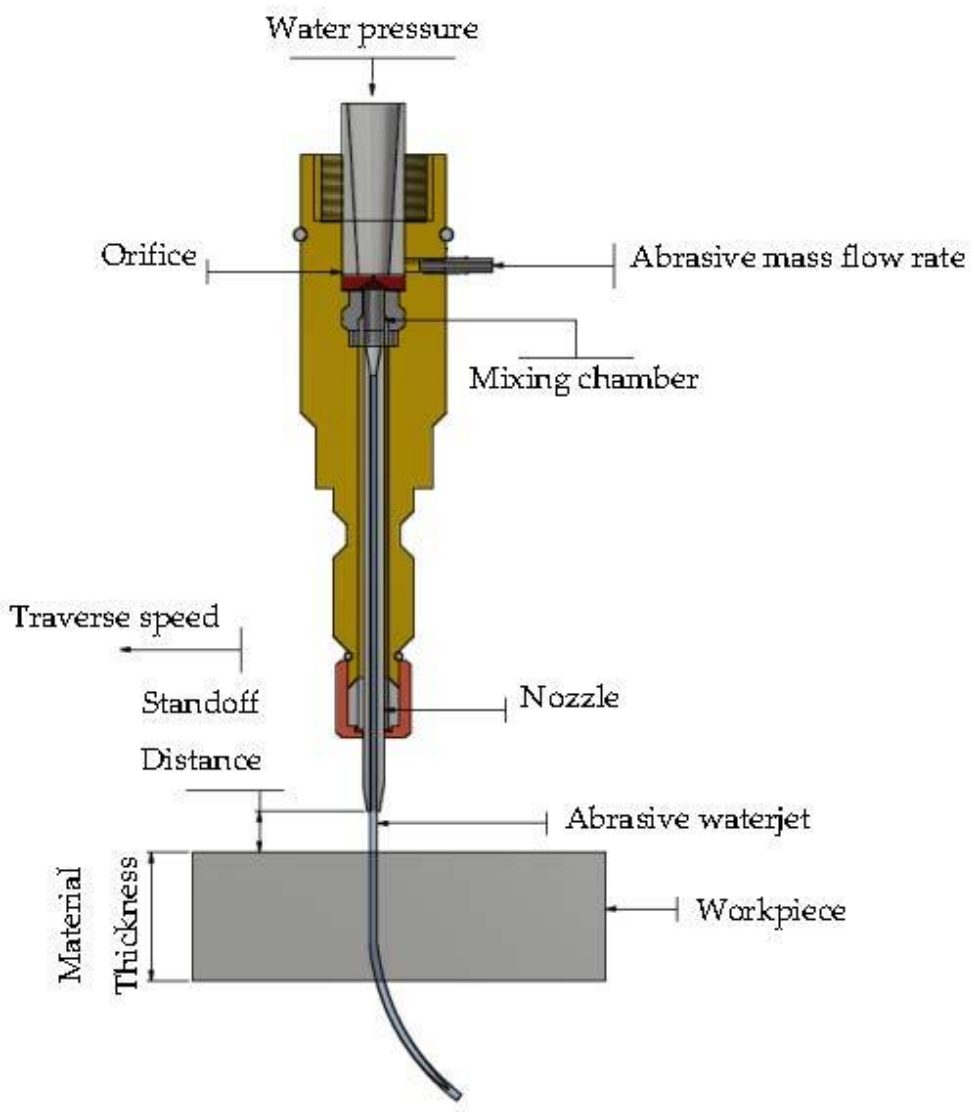

Figure 1. Schematic representation of AWJM cutting.

Abrasive waterjet is extensively used in machining of difficult-to-cut materials including titanium, steel and Inconel, with the capability to produce contour profiles in thickness of a workpiece possessing a value of up to $100 \mathrm{~mm}$ for stainless steel and up to $120 \mathrm{~mm}$ for aluminum [4]. For metallic materials, the material removal in an abrasive waterjet machine occurs through shear deformation, which is comprised of micro-chip formation, ploughing and rubbing [5]. Whilst AWJM exhibited feasibility in cutting difficult-to-machine materials, they still experience cutting issues such as high occurrences of surface roughness and low material removal rate. For instance, Veerappan et al. [6] studied abrasive waterjet performance in machining of nickel-based superalloy. The effects of cutting factors, such as traverse speed, waterjet pressure, standoff distance and abrasive mass flow rate against surface roughness and material removal rate were investigated. They obtained maximum surface roughness and material removal at a high level of waterjet pressure and abrasive mass flow rate. Therefore, both material removal rate and surface roughness increase with an increase in both the abrasive mass flow rate and waterjet pressure. Begic-Hajdarevic et al. [7] carried out experiments on the effect of traverse speed, abrasive mass flow rate, and material thickness on the surface roughness of AWJM of aluminum. Their experimental results indicated that increasing material thickness produces a higher value of surface roughness, particularly on the bottom area of the cut. They established that the traverse speed has no great effect on the surface roughness due to a minimal change occurred at the lower traverse speeds. Hence, increasing traverse speed increases the surface roughness value. Moreover, Bhandarkar et al. [8] presented an experimental investigation in machining Inconel 718 by AWJM. They considered input parameters i.e., traverse speed and pressure in achieving the required geometric accuracy and surface integrity. They concluded that a higher rate of traverse speed and lower pressure are the favorable conditions for achieving an improved roughness of the cut surface. 
An abrasive waterjet is predominantly applied for cutting hard-to-machine materials like austenitic stainless steels [9]. Due to its excellent corrosion resistance, austenitic stainless steel has been applied to a variety of industrial applications, such as architectural paneling, molding, trimming, construction materials for buildings, kitchen equipment, railings, chemical containers, aerospace, automotive etc. $[10,11]$. This capability of AISI $304 \mathrm{~L}$ is owing to its low carbon content and molybdenum, which restrains chloride corrosion and has low sensitivity to intergranular corrosion and good wear and friction properties [11]. AWJM is highly suitable for machining heat-sensitive materials such as austenitic stainless steel 304L due to its absence of the heat-affected zone [9]. Despite noteworthy advancements in the AWJM of austenitic stainless steel, there are still constraints and hindrances in utilizing this modern mechanical technology. Challenges associated with AWJM of austenitic stainless steel have been reported, particularly its low rate of the eroded material and high roughness of the cut surface. In an abrasive waterjet, cutting is generated by material removal caused by abrasive particles that hit the workpiece at high velocity and are influenced by the thickness and hardness of the target material [12]. Fundamentally, the productivity performance of AWJM is indicated by the removed material per unit of time [13]. In addition, surface roughness is the primary indicator of surface quality level which defines the scale of smoothness of the machined parts [14]. In general, the surface finishing profile cut by an abrasive waterjet is characterized by the degree of roughness it acquires during the machining process $[15,16]$. Comprehensive knowledge of the impacts of AWJM settings on the quality of the acquired cuts is an essential requisite in achieving precise cutting [17]. Hence, there is a necessity for optimization method as AWJM is faced with uncertainties in the selection of the most suitable parameter combination to improve quality and productivity relating to surface roughness and material removal rate. AWJM incorporates several independent input parameters that directly affect machine performance in terms of efficiency and quality. Generally, there are four sets of AWJM input parameters that include: (1) hydraulic parameters, (2) cutting parameters, (3) abrasive parameters and (4) mixing and acceleration parameters. The issues of material responses and behaviors, such as surface roughness, material removal rate and kerf taper angle to AWJM, have been studied since the emergence of abrasive waterjet applications in 1980s. Yet, it continues to be investigated as a means of effectively controlling AWJM input process parameters to achieve better cutting performance [18]. Accordingly, this determines the influence of AWJM process parameters on surface quality characteristics and material removal rate of difficult-to-cut materials such as AISI 304L.

The impacts of input parameters such as transverse speed, standoff distance, abrasive flow rate, and water pressure on material removal rate and surface roughness of austenitic stainless steel 304 by AWJM have been evaluated by Singh et al. [19]. Within the above study, an abrasive flow rate of $300 \mathrm{~g} / \mathrm{min}$, a waterjet pressure of $340 \mathrm{MPa}$, a stand-off distance of $2.5 \mathrm{~mm}$, and a traverse speed of $90 \mathrm{~mm} / \mathrm{min}$ were derived as the optimum process parameter values. Further, the above study divulged that traverse speed is the most significant factor, whilst standoff distance is the least significant factor affecting the selected responses. Löschnera et al. [20] have demonstrated an investigation of AWJM process parameters responses in reducing roughness in the straight cut surface of AWJM of AISI 3161 with $10 \mathrm{~mm}$ thickness. Their results revealed that employing a higher rate of cutting speed with decreasing kinetic energy of abrasive particles showed visible roughness in the lower cut part. Therefore, a lower rate of cutting speed prevents loss of kinetic energy of the abrasive water jet, resulting in a better quality of surface cut. Moreover, Karthik et al. [21] have studied the influences of water jet pressure, feed rate and abrasive flow rate on material removal rate and kerf top width in AWJM of stainless steel grade 304. Their experimental results indicate that higher values of material removal rate occur at higher values of water pressure and feed rate. Further, minimum kerf top width was achieved in the study by increasing the rate of waterjet pressure and decreasing value feed rate. Hence, their work has revealed that abrasive mass flow rate is an insignificant factor in material removal rate. Furthermore, Kmec et al. [22] have performed machining of AISI 304 with 
straight line directions, considering input parameters such as waterjet pressure, abrasive nozzle diameter, standoff distance, cutting feed rate, abrasive mass flow rate, and material thickness in order to minimize surface roughness. Their study has shown that a higher value of abrasive mass flow rate produces a large number of abrasives during cutting processes, resulting in lower surface roughness. However, increasing waterjet pressure with a wider diameter of abrasive nozzle generates inconsistent impacts between particles inside the stream and a loss in kinetic energy, leading to higher roughness value. Further, material thickness was shown to be an insignificant factor for surface roughness in the above study. Therefore, an increasing abrasive mass flow rate and decreasing values of waterjet pressure, cutting feed rate and standoff distance were shown as preferable for minimizing surface roughness.

A number of research studies have been conducted on the straight-slit cutting of austenitic stainless steel with an abrasive waterjet; however, very few studies have been conducted in contour cutting of difficult-to-cut and heat-sensitive materials like AISI 304L. The retardation of the jet inside the kerf of cut generates the deformation of the target material, specifically when machining corner and curvatures profiles [23]. Hence, this machining challenge requires further investigation.

In order to establish the optimum parameters in machining applications, Taguchibased optimization has been employed using Minitab software in this study. The Taguchi method is useful for discovering the most suitable combination of factors under specifically required experimental conditions, lessening the requisite number of experiments in conventional experiments as the number of process parameters increase [24]. In the Taguchi method, selection of suitable orthogonal array relies on aspects such as the number of input and response parameters along with correlations that are of key significance, figures of levels of data for input parameters; required objectives of the experiment; and constraints cited in the value and its performance [24,25]. This technique enables researchers to simultaneously establish independent and interrelating effects of several parameters affecting an outcome in any configuration. Therefore, in this study, the Taguchi method indicates S/N ratio calculation equations according to the maximization and minimization objectives in the abrasive waterjet contour cutting of AISI 304L.

Several studies relating to AWJM using the Taguchi method have demonstrated the effectiveness of this technique in establishing the optimal combination of process parameters in minimizing surface roughness. For instance, Kechagias et al. [5] have performed an experiment on AWJM using the Taguchi methodology, with results showing that by employing a lower level of traverse speed and standoff distance, a lower value of kerf width and surface roughness during AWJM of steel sheets (TRIP 800 HR-FH and TRIP $700 \mathrm{CR}-\mathrm{FH}$ ) was produced. In addition, an increasing thickness of material generated a decreasing value of surface roughness. Accordingly, the optimization of process parameters using the Taguchi method can be applied to various machining processes to provide sufficient approximation of performance and process control. Maneiah et al. [26] have presented the influence of various AWJM parameters such as standoff distance, feed rate, and abrasive flow rate in machining metal matrix composites (MMCs). The Taguchi L9 orthogonal array was shown to achieve the appropriate combination of designated process parameters to attain better surface quality characteristics. The authors determined that a feed rate of $135 \mathrm{~mm} / \mathrm{min}$, distance stand of $0.5 \mathrm{~mm}$, and abrasive flow rate of $450 \mathrm{gm} / \mathrm{min}$ were the most favorable process parameters to achieve lower surface roughness on MMCs. Thus, the response of the $\mathrm{S} / \mathrm{N}$ ratio indicates that feed rate provides greater impact on surface roughness, whilst stand of distance has minor impacts as compared to abrasive flow rate. Moreover, Sharma et al. [27] have presented an application of the Taguchi method to obtain desired surface roughness of aluminum AL-6061 via AWJM. The researchers of this study established that traverse speed has a greater influence on surface roughness, where pressure was the utmost impacting parameter for material removal rate. Hence, the application of an $\mathrm{L}_{16}$ orthogonal array can effectively optimize process variables for the achievement of desired surface roughness and material removal rates in AWJM processes. 
Furthermore, it should be noted that traditional experimental studies have been used to analyze the impacts of process parameters. Therefore, an optimization method is required in order to establish the best contributing factors. Amongst differing optimization techniques, the Taguchi method has become increasingly popular for developing engineered products [28]. The method addresses challenges with traditional experimental procedure of having a further increment in experimental works as the number of process parameters increases. With this specific advantage, this method minimizes time and cost spent in conducting experiments and in discovering significant factors.

From the above literature review, it is concluded that further investigation is required to comprehensively understand the impacts of process parameters in abrasive waterjet contour cutting to achieve better quality and higher productivity. In general, contour cutting is more challenging than linear cutting process. In addition, high-quality surface finish of the contour cut is an intensified requirement in various manufacturing industries, in particular, for difficult-to-cut metals such as such as stainless steel AISI 304L, where it is a significant performance indicator for machining. Therefore, this foregoing challenge requires continuous further investigation to be addressed.

In this research project, responses including material removal rate and surface roughness have been considered, as these are important quality characteristics of profile cut and aspects of productivity. To achieve these objectives, experimental and numerical studies have been conducted in this work to investigate interactions between AWJM input parameters, including water jet pressure, traverse speed, and abrasive mass flow rate, on surface roughness and rate of material removal in abrasive waterjet contour cutting of AISI 304L with differing level thicknesses. An optimization is implemented using Taguchi method in determining input parameter values resulting in minimum surface roughness and maximum material removal rate.

\section{Materials and Methods}

\subsection{Workpiece and Contour Cutting Profiles}

In this work, austenitic stainless steel (AISI) 340L was used at varied thicknesses of $4 \mathrm{~mm}, 8 \mathrm{~mm}$ and $12 \mathrm{~mm}$. The selected material thicknesses with uniform incremental gap were assigned to capture variations of AWJM behavior and to study its impacts on the machining characteristics of steel. The chemical composition and properties of AISI 304L are given in Tables 1 and 2 .

The widely used difficult-to-cut AISI 304L is distinguished from other alloy steels for its high strength, high corrosion and heat resistance because if its high contents of $\mathrm{Cr}$ and Ni [29]. Surface integrity and low material removal rate have been reported when machining AISI 304L, requiring improved industrial applications and further scientific research [30].

Table 1. Chemical composition in wt $\%$ of AISI 304L [11].

\begin{tabular}{llllllllll}
\hline \multicolumn{2}{l}{ Chemical Composition $(\mathbf{w t} \%)$. } \\
\hline $\mathrm{Fe}$ & $\mathrm{C}$ & $\mathrm{Mn}$ & $\mathrm{Si}$ & $\mathrm{Mo}$ & $\mathrm{Co}$ & $\mathrm{Cr}$ & $\mathrm{Cu}$ & $\mathrm{Ni}$ & Others \\
\hline 70.780 & 0.025 & 1.140 & 0.410 & 0.360 & 0.210 & 18.40 & 0.180 & 8.190 & 0.305 \\
\hline
\end{tabular}

Table 2. Mechanical Properties of AISI 304L [11,31].

\begin{tabular}{ll}
\hline Properties of AISI 304L & \\
\hline Hardness, Rockwell B & 82 \\
\hline Tensile Strength, Ultimate, MPa & 564 \\
\hline Tensile Strength, Yield, MPa & 210 \\
\hline Elongation at Break \% & $58 \%$ \\
\hline Modulus of Elasticity, GPa & $193-200$ \\
\hline
\end{tabular}


In general, contour cutting is employed in steel fabrication industries because of its ability to deal with complicated and complex geometries, enabling the production of various products. The contour cutting process is mostly applied in metalworking industries as compared with the straight-slit cutting process, involving various convex and concave arcs and straight-lines to form a particular geometry. In this research, four levels of inner and outer arcs and straight-lines have been used to study the impacts of contour profiles on abrasive waterjet machining responses.

Figure 2 presents the cutting path containing the identified profiles for the execution of the Taguchi design of experiments and confirmatory tests. Figure 2a summarizes the execution of 27 experimental runs, while Figure $2 b$ illustrates a confirmatory test using the obtained optimum combination of input parameters.

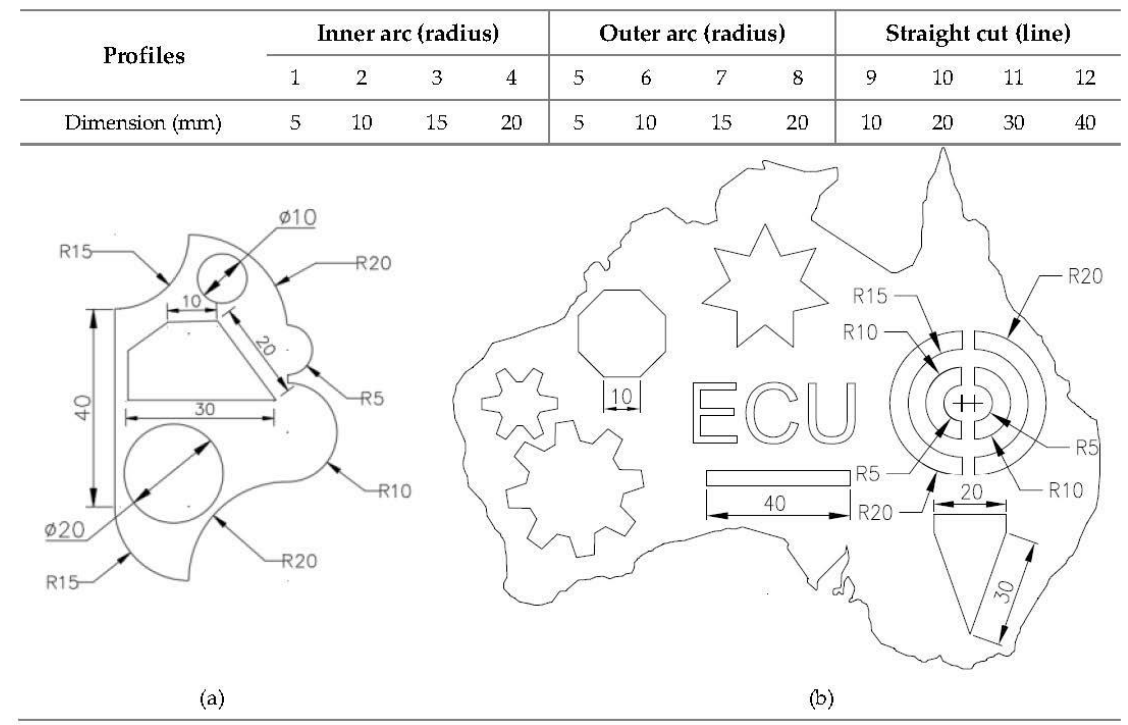

Figure 2. AWJM contour cutting path for (a) Taguchi $\mathrm{L}_{27}$ tests [32]. (b) Confirmation test.

The abovementioned profiles were selected to accommodate a broad array of complicated machining profiling applications. A straight-line cut ranging from 10 to $40 \mathrm{~mm}$ is adequate to acquire a constant phase of feed rate, covering the acceleration and retardation phase [33]. The levels of arcs profile, i.e., $10-40 \mathrm{~mm}$, showed manifestation of surface roughness, low machining rate and imprecision of cut geometries from previous works [34-36], indicating the necessity for further studies, particularly for hard-to-cut materials such as AISI 304L.

\subsection{AWJ Machining Setup and Parameters}

The experiments were conducted on an OMAX-MAXIEM 1515 abrasive waterjet machine. Clamping was required to hold the workpiece in the catcher tank. The water temperature was maintained at $50-32{ }^{\circ} \mathrm{C}$ during cutting operations, using a chiller tank. These machine components included a pneumatically-controlled valve, an abrasive hopper with gravity feed type, an abrasive feeder system and a cutting table of $1575 \mathrm{~mm} \times 1575 \mathrm{~mm}$. To attain accuracy in contour cutting, an appropriate assignment of the process parameters is critical. In this research, waterjet pressure, abrasive mass flow rate, traverse speed and material thickness have been considered as variable input parameters at three different levels.

The machining setup and input parameters employed in the cutting test of AISI 304L are given in Table 3. The designated levels of variable and constant input parameters were based on consensus from recommended control ranges for abrasive waterjet machining in previous investigations [37-39]. Abrasive type efficiency is indicated by level of hardness; thus, a more rigid material requires a harder abrasive particle [15,40]. A Garnet of 80 mesh size with a hardness of MOHS 7-8 was used in this study due to its better surface integrity results, in accordance with previous related studies [15]. 
Table 3. Machine specifications and cutting input parameters.

\begin{tabular}{lll}
\hline Abrasive Waterjet Conditions & Details & Range/Values \\
\hline OMAX MAXIEM 1515 & Max Pressure, MPA & \\
& Max Traverse Speed, mm/min & 413.7 \\
& Table Size $(\mathrm{L} \times \mathrm{W}), \mathrm{mm}$ & 12,700 \\
& XY Cutting Envelope, $\mathrm{mm}$ & $2235 \times 1727$ \\
& z-Axis travel, mm & $1575 \times 1575$ \\
& & 305 \\
Variable cutting input parameters & Abrasive mass flow rate, g/min & $300,400,500$ \\
& Waterjet pressure, MPa & $200,250,300$ \\
& Traverse speed, mm/min & $90,120,150$ \\
& Material thickness, mm & $4,8,12$ \\
& & \\
Constant cutting input parameters & Orifice diameter, mm & 2.8 \\
& Abrasive type & Garnet \\
& Abrasive mesh number, \# & 80 \\
& Standoff distance, mm & 1.5 \\
\hline
\end{tabular}

In this work, three major steps were executed, comprising of abrasive waterjet contour cutting experiments, measuring of results and optimization. The overall experimental and optimization procedures are shown in Figure 3. The defined machining conditions of OMAX MAXIEM 1515 are employed to execute contour cutting of AISI 304L experiments. The roughness resulted from the machined surfaces are measured using the TR200 model surface roughness tester. Subsequently, the surface images of the cut profiles were captured and topographically analyzed using LEICA M80. The kerf widths of the cut workpiece, which were the function of material removal rate, were measured using a LEICA M80 optical microscope model. Further, the Taguchi $\mathrm{S} / \mathrm{N}$ ratio was employed to optimize the process parameters using MINITAB 19 software (version 19.1, Minitab Pty Ltd. Sydney, Australia).

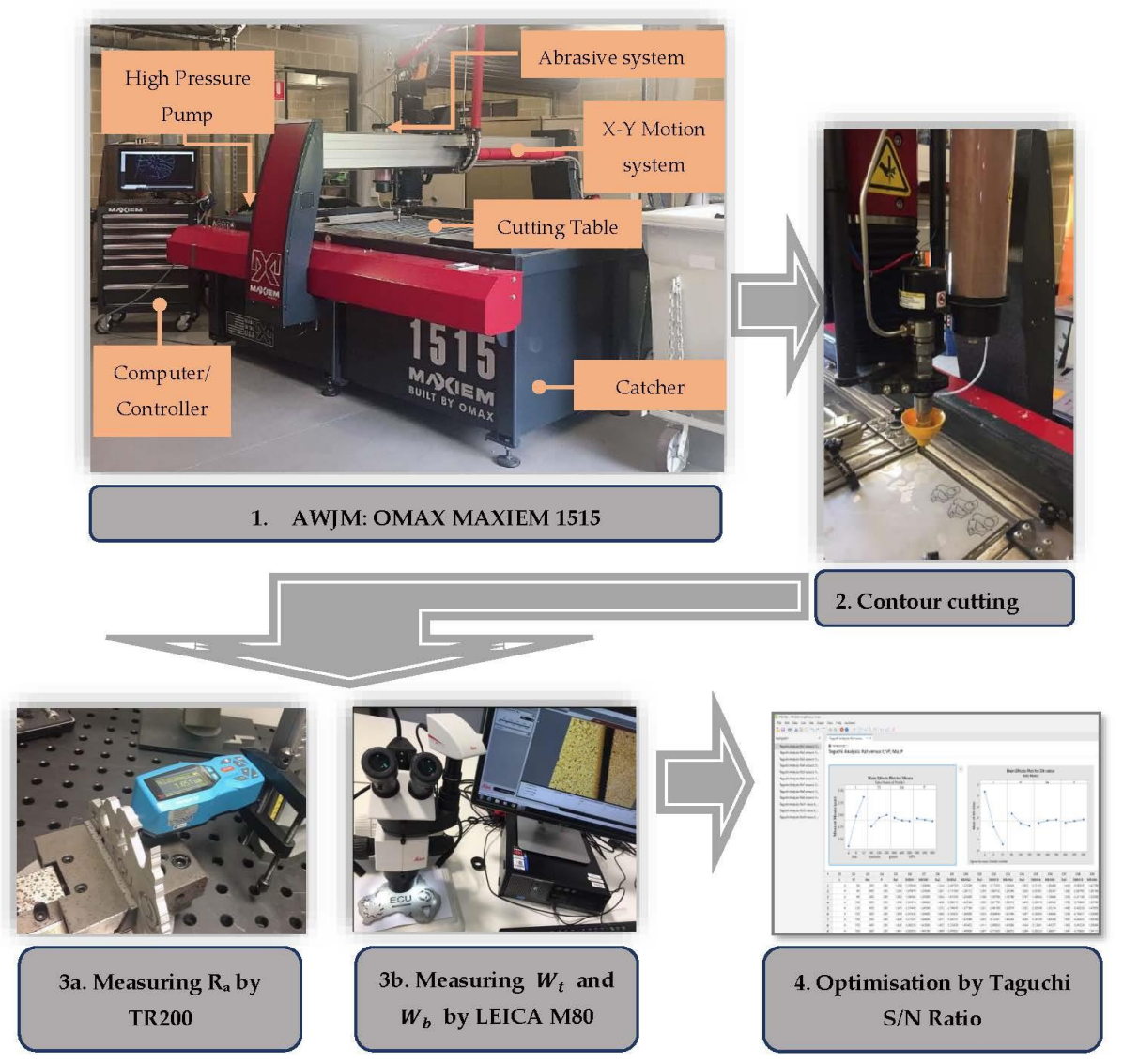

Figure 3. AWJM contour cutting experiment and analysis setup. 
The rate of material removal and surface roughness are selected as output parameters to be optimized. The rate of material removal, which is the volume of metal eroded from the target workpiece per unit of time, is quantified by traverse speed, width of kerf and penetration of cut. Thus, material removal rate was calculated using Equation (1) [41].

$$
M R R=h t . W . v f
$$

where kerf width is calculated by the following formula: $W=\frac{W_{t}+W_{b}}{2}$.

\subsection{Design of Experiment}

To accommodate several variable parameters in the abrasive waterjet contour cutting of AISI 304L, a standardized Taguchi Orthogonal array $\mathrm{L}_{27}$ was employed in this study to execute the experiment using four factors with three levels, as shown in Table 4.

Table 4. The $\mathrm{L}_{27}$ orthogonal array of Taguchi.

\begin{tabular}{|c|c|c|c|c|}
\hline Exp. & Input Parameters & & & \\
\hline No. & $\begin{array}{l}\text { Material Thickness, } t \\
(\mathbf{m m})\end{array}$ & $\begin{array}{l}\text { Traverse Speed, } V_{f} \\
(\mathrm{~mm} / \mathrm{min})\end{array}$ & $\begin{array}{l}\text { Abrasive Mass } \\
\text { Flow Rate, ma } \\
\text { (g/min) }\end{array}$ & $\begin{array}{c}\text { Waterjet Pressure, } P \\
(\mathrm{MPa})\end{array}$ \\
\hline 1 & 4 & 90 & 300 & 200 \\
\hline 2 & 4 & 90 & 400 & 250 \\
\hline 3 & 4 & 90 & 500 & 300 \\
\hline 4 & 4 & 120 & 300 & 250 \\
\hline 5 & 4 & 120 & 400 & 300 \\
\hline 6 & 4 & 120 & 500 & 200 \\
\hline 7 & 4 & 150 & 300 & 300 \\
\hline 8 & 4 & 150 & 400 & 200 \\
\hline 9 & 4 & 150 & 500 & 250 \\
\hline 10 & 8 & 90 & 300 & 200 \\
\hline 11 & 8 & 90 & 400 & 250 \\
\hline 12 & 8 & 90 & 500 & 300 \\
\hline 13 & 8 & 120 & 300 & 250 \\
\hline 14 & 8 & 120 & 400 & 300 \\
\hline 15 & 8 & 120 & 500 & 200 \\
\hline 16 & 8 & 150 & 300 & 300 \\
\hline 17 & 8 & 150 & 400 & 200 \\
\hline 18 & 8 & 150 & 500 & 250 \\
\hline 19 & 12 & 90 & 300 & 200 \\
\hline 20 & 12 & 90 & 400 & 250 \\
\hline 21 & 12 & 90 & 500 & 300 \\
\hline 22 & 12 & 120 & 300 & 250 \\
\hline 23 & 12 & 120 & 400 & 300 \\
\hline 24 & 12 & 120 & 500 & 200 \\
\hline 25 & 12 & 150 & 300 & 300 \\
\hline 26 & 12 & 150 & 400 & 200 \\
\hline 27 & 12 & 150 & 500 & 250 \\
\hline
\end{tabular}

Relying on this design, 27 experimental runs were executed with combination levels for each variable parameter. The Taguchi method has a diverse signal-to-noise $(\mathrm{S} / \mathrm{N})$ ratio, including "the larger the better", "the nominal the better" and "the smaller the better" [42]. This work's objectives sought to obtain results with minimum surface roughness and maximum material removal rate. Therefore, signal-to-noise ratios have been calculated according to the "lower-is-the better" category for surface roughness and "higher-is-thebetter" for material removal rate. In computing SNR (signal-to noise ratios), the lower- 
the-better and the higher-the-better categories are expressed in Equations (2) and (3), respectively [43].

$$
\begin{gathered}
S / N_{S R}=\eta_{i j}=-10 \log \left(\frac{1}{n_{i}} \sum_{i=1}^{n}\left(y_{i j}\right)^{2}\right) \\
S / N_{M R R}=\eta_{i j}=-10 \log \left(\frac{1}{n_{i}} \sum_{i=1}^{n} \frac{1}{\left(y_{i j}\right)^{2}}\right),
\end{gathered}
$$

where $y_{i}$ is the result obtained in present; $\eta$ shows the number of tests.

Furthermore, Analysis of variance (ANOVA) was utilized to establish the percentage contribution of each input parameter regarding surface roughness and material removal rate. $p$-Values estimated at more than 0.05 or $5 \%$ were considered insignificant because ANOVA in this research was run with a confidence interval of $95 \%$, in alignment with previous studies [24,44-46].

\section{Results and Discussions}

3.1. Effects of Input Parameters on Surface Roughness and Material Removal Rate

The cut surfaces produced during AWJM of AISI 304L are topographically presented in Figures 4-12. The cut samples from a straight profile demonstrated different material responses towards the application of three levels of traverse speed, waterjet pressure and abrasive mass flow rate for $4 \mathrm{~mm}, 8 \mathrm{~mm}$ and $12 \mathrm{~mm}$ thickness of AISI 304L.

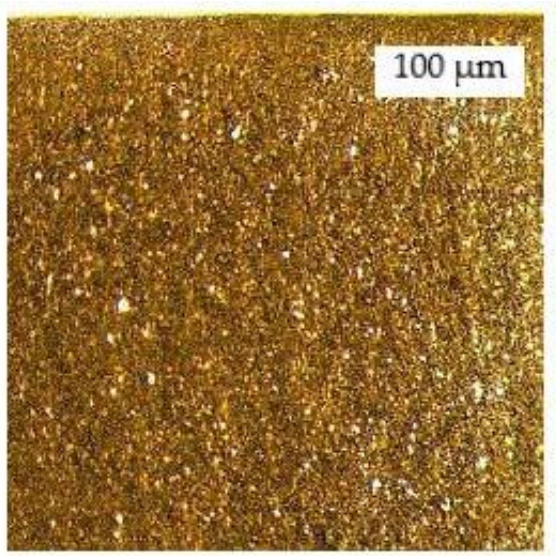

(a) $90 \mathrm{~mm} / \mathrm{min}$

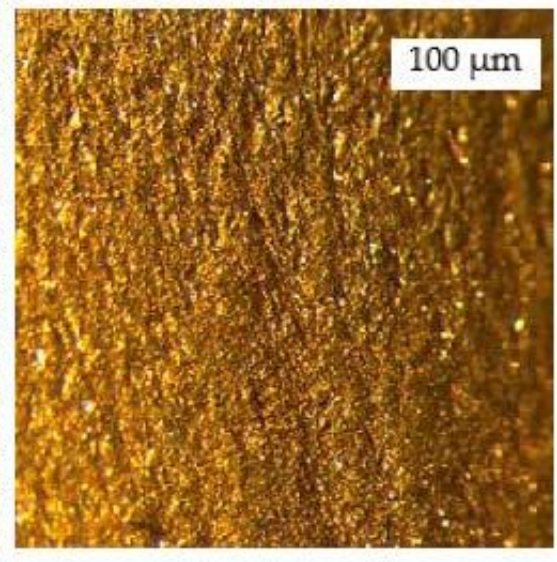

(b) $120 \mathrm{~mm} / \mathrm{min}$

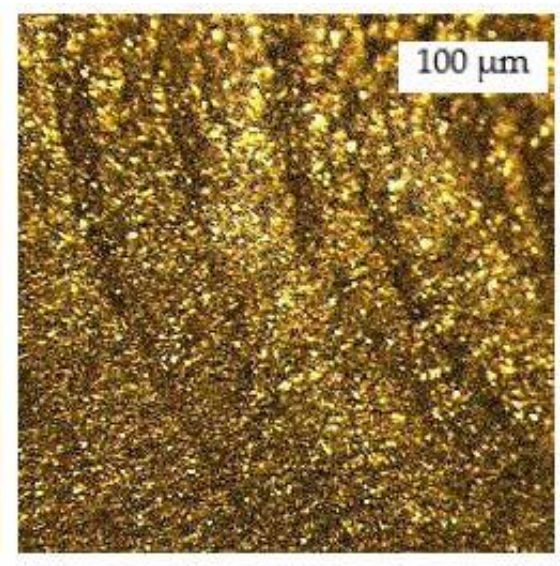

(c) $150 \mathrm{~mm} / \mathrm{min}$

Figure 4. Topography of AISI 304L cut surface with $4 \mathrm{~mm}$ thickness using varied traverse speed.

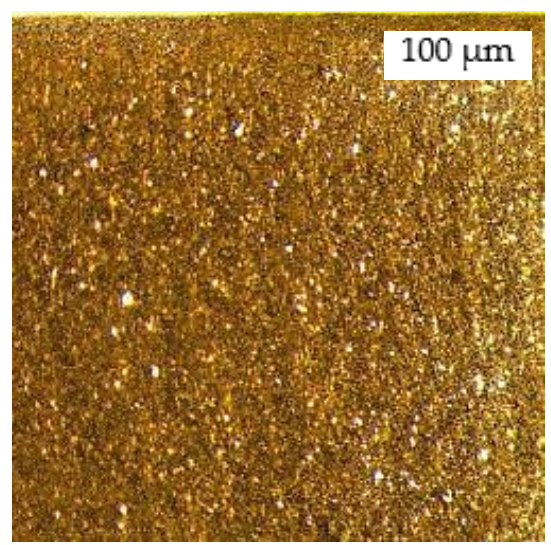

(a) $90 \mathrm{~mm} / \mathrm{min}$

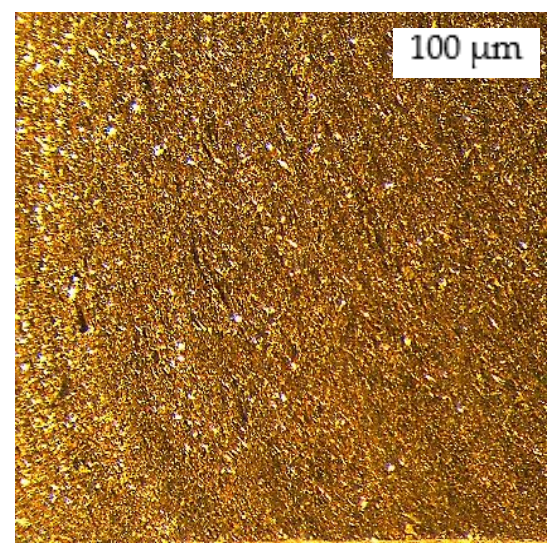

(b) $120 \mathrm{~mm} / \mathrm{min}$

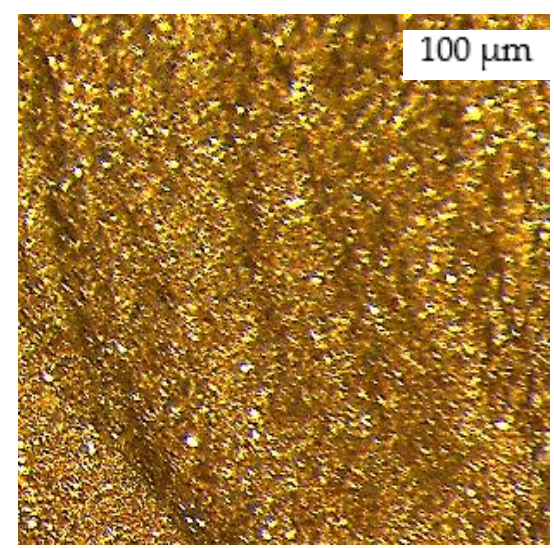

(c) $150 \mathrm{~mm} / \mathrm{min}$

Figure 5. Topography of AISI 304L cut surface with $8 \mathrm{~mm}$ thickness using varied traverse speed. 


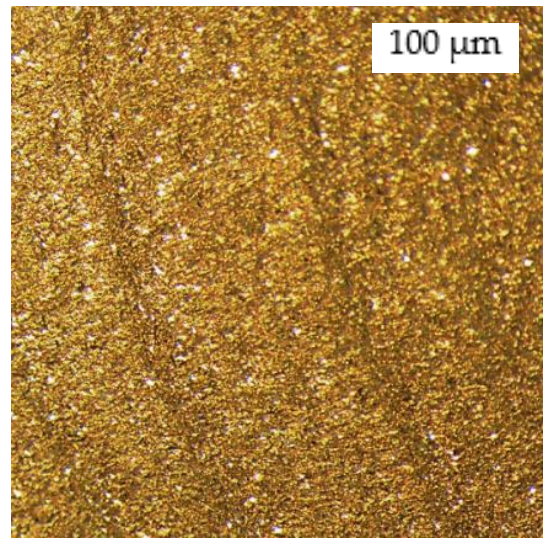

(a) $90 \mathrm{~mm} / \mathrm{min}$

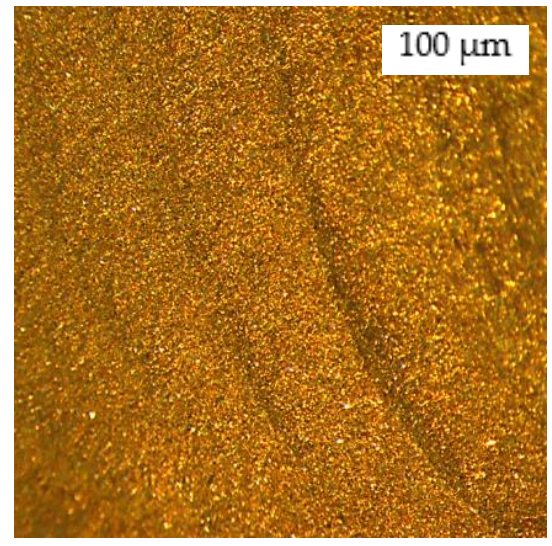

(b) $120 \mathrm{~mm} / \mathrm{min}$

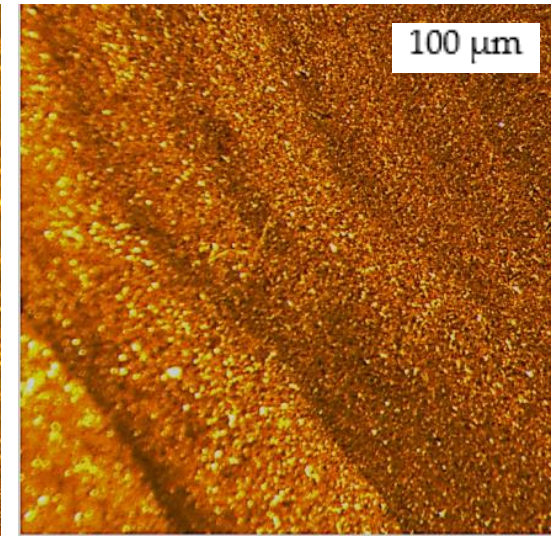

(c) $150 \mathrm{~mm} / \mathrm{min}$

Figure 6. Topography of AISI 304L cut surface with $12 \mathrm{~mm}$ thickness using varied traverse speed.

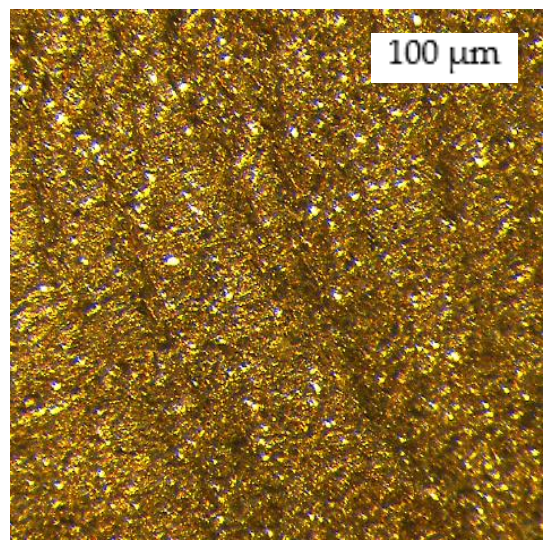

(a) $200 \mathrm{MPa}$

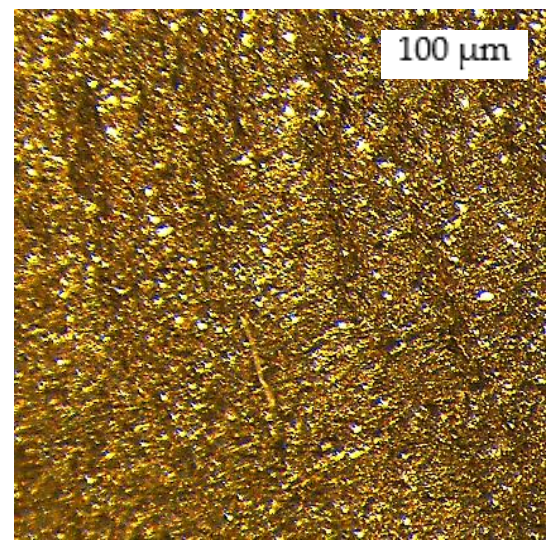

(b) $250 \mathrm{MPa}$

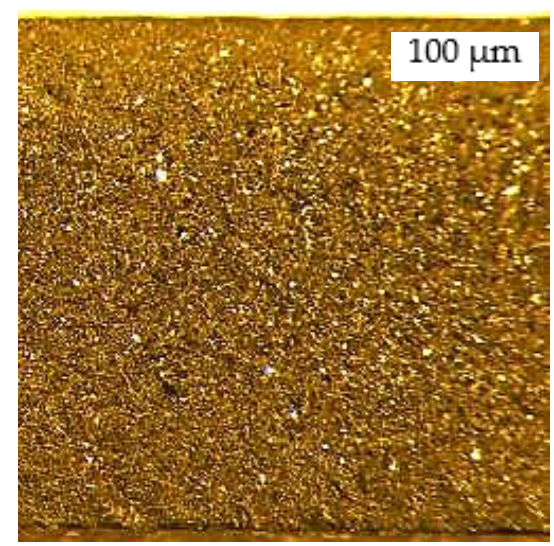

(c) $300 \mathrm{MPa}$

Figure 7. Topography of AISI 304L cut surface with $4 \mathrm{~mm}$ thickness using varied waterjet pressure.

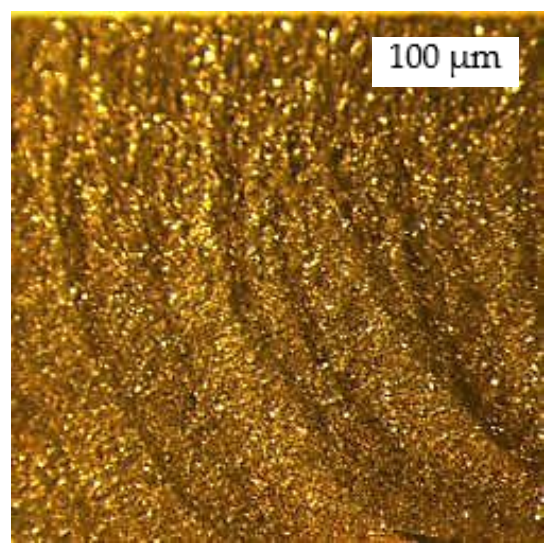

(a) $200 \mathrm{MPa}$

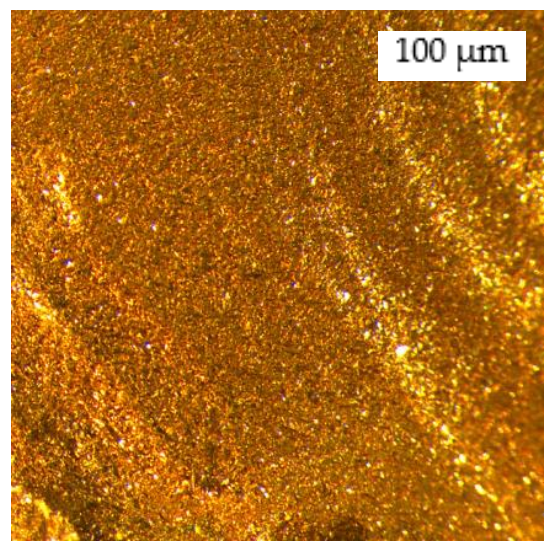

(b) $250 \mathrm{MPa}$

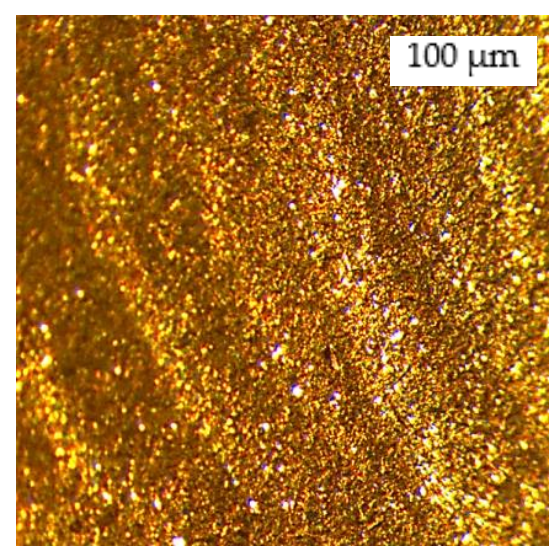

(c) $300 \mathrm{MPa}$

Figure 8. Topography of AISI 304L cut surface with $8 \mathrm{~mm}$ thickness using varied waterjet pressure. 


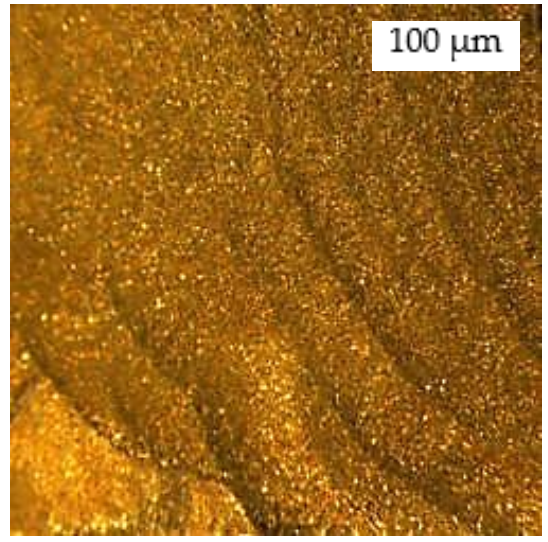

(a) $200 \mathrm{MPa}$

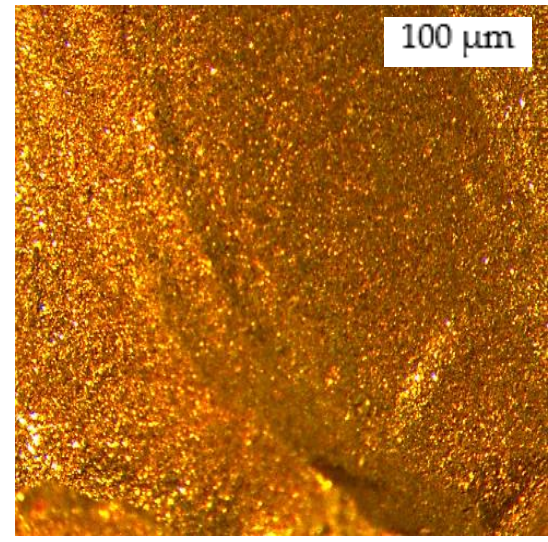

(b) $250 \mathrm{MPa}$

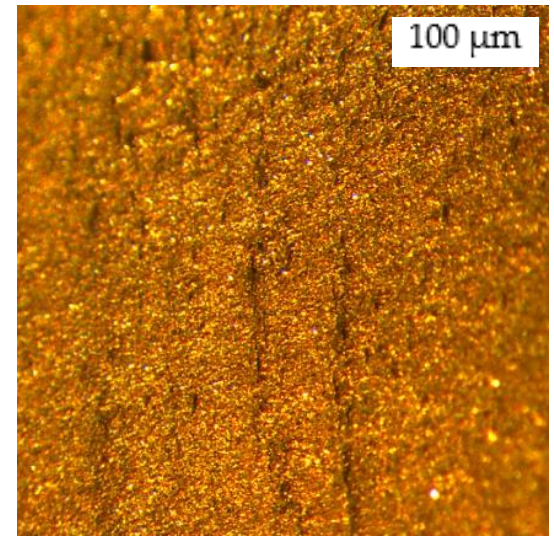

(c) $300 \mathrm{MPa}$

Figure 9. Topography of AISI 304L cut surface with $12 \mathrm{~mm}$ thickness using varied waterjet pressure.

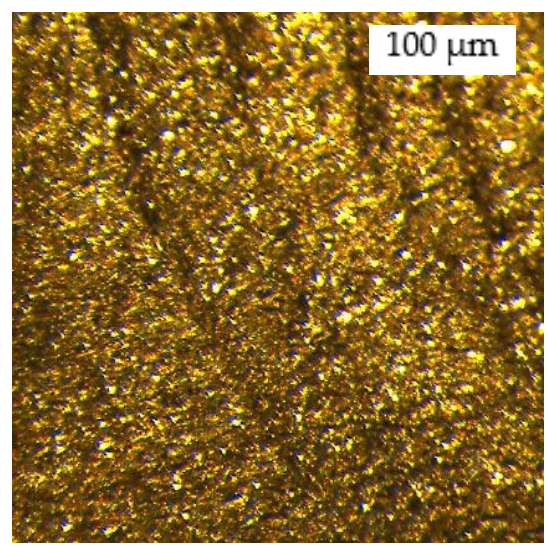

(a) $300 \mathrm{~g} / \mathrm{min}$

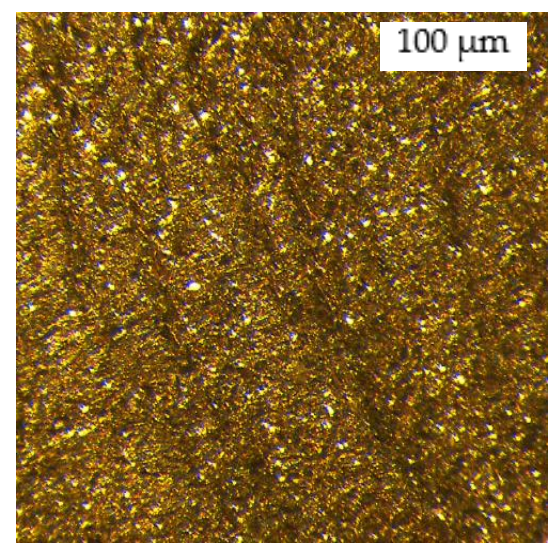

(b) $400 \mathrm{~g} / \mathrm{min}$

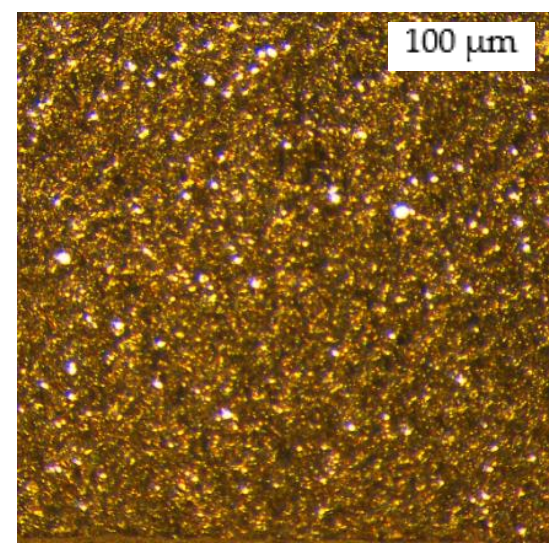

(c) $500 \mathrm{~g} / \mathrm{min}$

Figure 10. Topography of AISI 304L cut surface with $4 \mathrm{~mm}$ thickness using varied Abrasive mass flow rate.

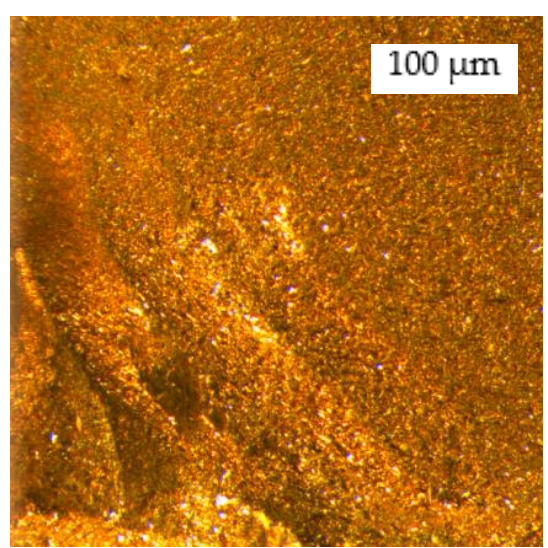

(a) $300 \mathrm{~g} / \mathrm{min}$

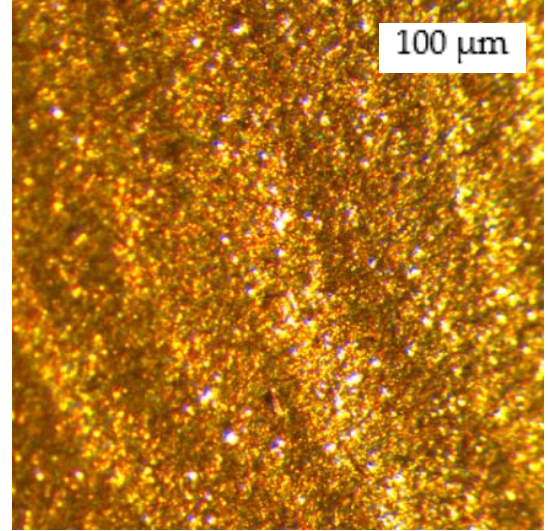

(b) $400 \mathrm{~g} / \mathrm{min}$

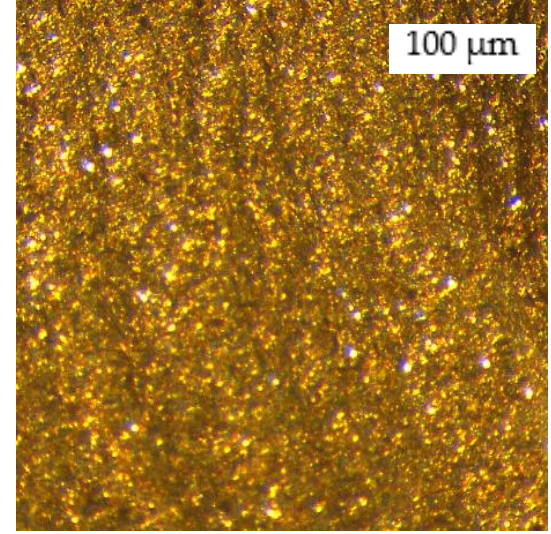

(c) $500 \mathrm{~g} / \mathrm{min}$

Figure 11. Topography of AISI 304L cut surface with $8 \mathrm{~mm}$ thickness using varied Abrasive mass flow rate. 


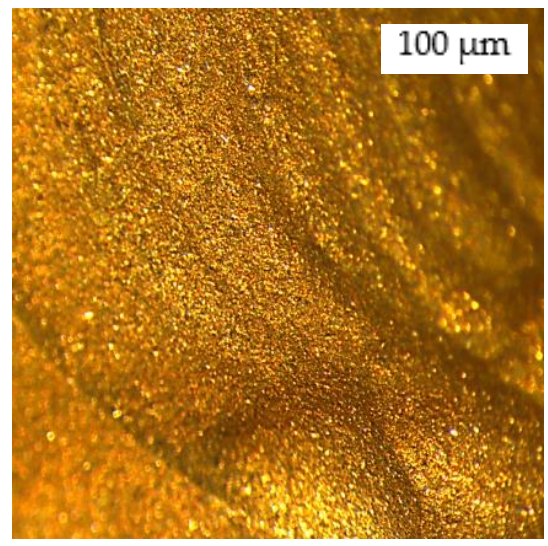

(a) $300 \mathrm{~g} / \mathrm{min}$

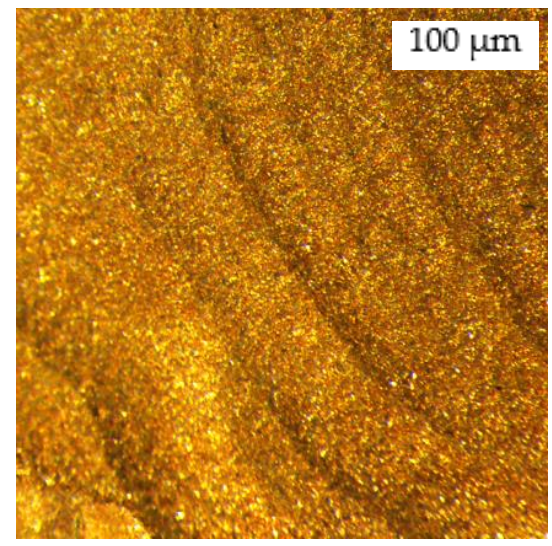

(b) $400 \mathrm{~g} / \mathrm{min}$

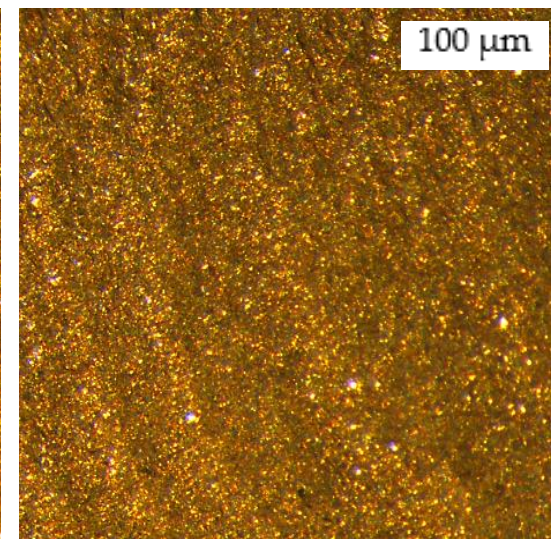

(c) $500 \mathrm{~g} / \mathrm{min}$

Figure 12. Topography of AISI 304L cut surface with $12 \mathrm{~mm}$ thickness using varied Abrasive mass flow rate.

Figures 4-6 showed that surface roughness and striation are visibly higher as the traverse speed value increases from $90 \mathrm{~mm} / \mathrm{min}$ to $150 \mathrm{~mm} / \mathrm{min}$ with constant values for waterjet pressure and abrasive mass flow rate of $300 \mathrm{MPa}$ and $500 \mathrm{~g} / \mathrm{min}$, respectively. The cut samples displayed similar material behavior of incrementing occurrences of surface roughness as the traverse speed value increases. This is due to the fact that the increasing rate of traverse speed is losing the number of abrasive particles leading to the roughness of the cut surface [47]. The material responses of AISI 304L against waterjet pressure were presented in Figures 7-9. The cut specimens revealed comparable evidence of decreasing surface roughness as the waterjet pressure value increases from $200 \mathrm{MPa}$ to $300 \mathrm{MPa}$ with constant values for traverse speed and abrasive mass flow rate of $90 \mathrm{~mm} / \mathrm{min}$ and $500 \mathrm{~g} / \mathrm{min}$, respectively. The increasing value of waterjet pressure denotes a higher energy reinforcing a larger amount of abrasive particles which results in lesser striation on the cut surface [5]. Figures 10-12 exhibited a similar trend of decreasing waviness pattern on the cut surface, as the abrasive mass flow rate is increasing from $300 \mathrm{~g} / \mathrm{min}$ to $500 \mathrm{~g} / \mathrm{min}$ with constant rates for traverse speed and waterjet pressure of $90 \mathrm{~mm} / \mathrm{min}$ and $300 \mathrm{MPa}$, respectively. A higher abrasive mass flow results in a breakdown of abrasive particles into smaller scales, producing more sharp edges which are responsible for decreasing the roughness of the cut surface [40].

Images presented in Figures 4-12, denote higher visibility of surface striations and waviness as the material thickness increases. It is observed that striations are turned in the opposite direction of the cutting path. The curvature of striations depends on the AWJM cutting velocity and material type [48]. The topmost cut surface demonstrated smoothness and the bottom part is rough with wavy lines patterns. The striation is formed due to the movements of the jets during the machining process, which is linked to the changing of the cutting path or profiles [49]. In addition, the wavy distribution of the kinetic energy of the intergranular abrasive inside the abrasive waterjet leads to the formation of striation on the surface cut. Hence, as the depth of cut or material thickness increases, the kinetic energy decreases generating a higher occurrence of wavy lines. The abrasive waterjet holds high kinetic energy with a large number of abrasive particles from the beginning of the erosion process that gradually subsiding during machining, resulting in manifestations of higher surface roughness [47]. Topographically, material thickness is the topmost impacting parameter followed by the waterjet pressure, abrasive mass flow rate and traverse speed.

The experimental results presented in Table 5 display the response of surface roughness $\left(R_{\mathrm{a}}\right)$ for various levels of material thickness $(t)$, abrasive flow rate $\left(\mathrm{m}_{\mathrm{a}}\right)$, waterjet pressure $(P)$ and traverse speed $\left(V_{f}\right)$. The lowest values of $R_{\mathrm{a}}$ achieved in abrasive waterjet contour cutting of AISI 304L were $1.142 \mu \mathrm{m}$ for $4 \mathrm{~mm}, 1.529 \mu \mathrm{m}$ for $8 \mathrm{~mm}$, and $1.993 \mu \mathrm{m}$ for $12 \mathrm{~mm}$ material thicknesses. 
Table 5. The $\mathrm{L}_{27}$ orthogonal array of Taguchi for surface roughness results.

\begin{tabular}{|c|c|c|c|c|c|c|c|c|c|c|c|c|c|c|c|c|}
\hline \multirow{3}{*}{$\begin{array}{l}\text { Exp. } \\
\text { No. }\end{array}$} & \multicolumn{4}{|c|}{ Input Parameters } & \multicolumn{12}{|c|}{ Output Parameter $\left(\mathbf{R}_{\mathrm{a}}=\mu \mathrm{m}\right)$} \\
\hline & \multirow{2}{*}{$t(\mathrm{~mm})$} & \multirow{2}{*}{$\begin{array}{c}V_{f} \\
(\mathrm{~mm} / \mathrm{min})\end{array}$} & \multirow{2}{*}{$\underset{(\mathrm{g} / \mathrm{min})}{\mathrm{m}_{\mathrm{a}}}$} & \multirow{2}{*}{$\begin{array}{c}P \\
(\mathrm{MPa})\end{array}$} & \multicolumn{12}{|c|}{ Profiles } \\
\hline & & & & & 1 & 2 & 3 & 4 & 5 & 6 & 7 & 8 & 9 & 10 & 11 & 12 \\
\hline 1 & 4 & 90 & 300 & 200 & 1.298 & 1.324 & 1.284 & 1.305 & 1.428 & 1.396 & 1.356 & 1.248 & 1.285 & 1.250 & 1.248 & 1.235 \\
\hline 2 & 4 & 90 & 400 & 250 & 1.256 & 1.281 & 1.243 & 1.263 & 1.382 & 1.351 & 1.313 & 1.208 & 1.243 & 1.210 & 1.208 & 1.195 \\
\hline 3 & 4 & 90 & 500 & 300 & 1.200 & 1.204 & 1.168 & 1.187 & 1.320 & 1.291 & 1.254 & 1.154 & 1.188 & 1.156 & 1.154 & 1.142 \\
\hline 4 & 4 & 120 & 300 & 250 & 1.398 & 1.426 & 1.383 & 1.405 & 1.538 & 1.504 & 1.461 & 1.344 & 1.384 & 1.346 & 1.344 & 1.331 \\
\hline 5 & 4 & 120 & 400 & 300 & 1.345 & 1.372 & 1.331 & 1.352 & 1.480 & 1.447 & 1.406 & 1.293 & 1.332 & 1.295 & 1.293 & 1.280 \\
\hline 6 & 4 & 120 & 500 & 200 & 1.399 & 1.468 & 1.424 & 1.447 & 1.539 & 1.505 & 1.462 & 1.345 & 1.385 & 1.347 & 1.345 & 1.332 \\
\hline 7 & 4 & 150 & 300 & 300 & 1.448 & 1.477 & 1.433 & 1.456 & 1.593 & 1.558 & 1.513 & 1.392 & 1.434 & 1.394 & 1.392 & 1.378 \\
\hline 8 & 4 & 150 & 400 & 200 & 1.426 & 1.455 & 1.411 & 1.434 & 1.569 & 1.534 & 1.490 & 1.371 & 1.412 & 1.373 & 1.371 & 1.357 \\
\hline 9 & 4 & 150 & 500 & 250 & 1.401 & 1.409 & 1.367 & 1.389 & 1.541 & 1.507 & 1.464 & 1.347 & 1.387 & 1.349 & 1.347 & 1.333 \\
\hline 10 & 8 & 90 & 300 & 200 & 1.886 & 1.924 & 1.866 & 1.896 & 2.075 & 2.029 & 1.971 & 1.813 & 1.867 & 1.816 & 1.813 & 1.795 \\
\hline 11 & 8 & 90 & 400 & 250 & 1.825 & 1.861 & 1.806 & 1.835 & 2.007 & 1.963 & 1.907 & 1.755 & 1.807 & 1.757 & 1.755 & 1.737 \\
\hline 12 & 8 & 90 & 500 & 300 & 1.744 & 1.576 & 1.529 & 1.553 & 1.918 & 1.876 & 1.822 & 1.676 & 1.726 & 1.679 & 1.676 & 1.660 \\
\hline 13 & 8 & 120 & 300 & 250 & 2.031 & 2.072 & 2.010 & 2.042 & 2.234 & 2.185 & 2.123 & 1.953 & 2.011 & 1.956 & 1.953 & 1.933 \\
\hline 14 & 8 & 120 & 400 & 300 & 1.954 & 1.893 & 1.836 & 1.866 & 2.150 & 2.102 & 2.042 & 1.879 & 1.935 & 1.882 & 1.879 & 1.860 \\
\hline 15 & 8 & 120 & 500 & 200 & 2.033 & 2.073 & 2.011 & 2.044 & 2.236 & 2.187 & 2.124 & 1.954 & 2.012 & 1.958 & 1.954 & 1.935 \\
\hline 16 & 8 & 150 & 300 & 300 & 2.104 & 2.146 & 2.082 & 2.115 & 2.314 & 2.263 & 2.199 & 2.023 & 2.083 & 2.026 & 2.023 & 2.003 \\
\hline 17 & 8 & 150 & 400 & 200 & 2.072 & 2.113 & 2.050 & 2.083 & 2.279 & 2.229 & 2.165 & 1.992 & 2.051 & 1.995 & 1.992 & 1.972 \\
\hline 18 & 8 & 150 & 500 & 250 & 2.036 & 1.998 & 1.938 & 1.969 & 2.239 & 2.19 & 2.127 & 1.957 & 2.015 & 1.960 & 1.957 & 1.938 \\
\hline 19 & 12 & 90 & 300 & 200 & 2.265 & 2.310 & 2.241 & 2.277 & 2.492 & 2.437 & 2.367 & 2.178 & 2.242 & 2.181 & 2.178 & 2.156 \\
\hline 20 & 12 & 90 & 400 & 250 & 2.192 & 2.236 & 2.169 & 2.203 & 2.411 & 2.358 & 2.290 & 2.107 & 2.170 & 2.111 & 2.107 & 2.086 \\
\hline 21 & 12 & 90 & 500 & 300 & 2.094 & 2.136 & 2.072 & 2.105 & 2.303 & 2.253 & 2.188 & 2.013 & 2.073 & 2.017 & 2.013 & 1.993 \\
\hline 22 & 12 & 120 & 300 & 250 & 2.440 & 2.408 & 2.336 & 2.373 & 2.684 & 2.625 & 2.549 & 2.345 & 2.415 & 2.349 & 2.345 & 2.322 \\
\hline 23 & 12 & 120 & 400 & 300 & 2.347 & 2.308 & 2.239 & 2.275 & 2.582 & 2.525 & 2.453 & 2.256 & 2.324 & 2.260 & 2.256 & 2.234 \\
\hline 24 & 12 & 120 & 500 & 200 & 2.441 & 2.490 & 2.415 & 2.454 & 2.685 & 2.626 & 2.551 & 2.347 & 2.417 & 2.351 & 2.347 & 2.324 \\
\hline 25 & 12 & 150 & 300 & 300 & 2.527 & 2.658 & 2.578 & 2.620 & 2.780 & 2.718 & 2.641 & 2.429 & 2.502 & 2.433 & 2.429 & 2.405 \\
\hline 26 & 12 & 150 & 400 & 200 & 2.488 & 2.538 & 2.462 & 2.502 & 2.737 & 2.677 & 2.600 & 2.392 & 2.464 & 2.396 & 2.392 & 2.368 \\
\hline 27 & 12 & 150 & 500 & 250 & 2.445 & 2.393 & 2.321 & 2.359 & 2.689 & 2.630 & 2.555 & 2.350 & 2.420 & 2.354 & 2.350 & 2.327 \\
\hline
\end{tabular}

Surface roughness corresponding to $\mathrm{S} / \mathrm{N}$ ratio values for this study is listed in Table A1 of the Appendix A. The results indicate the feasibility of obtaining lowest surface roughness with higher values of waterjet pressure and abrasive mass flow rate at a rate of $300 \mathrm{MPa}$ and $500 \mathrm{~g} / \mathrm{min}$, respectively. In AWJM, higher waterjet pressure leads to a greater amount of abrasives, providing a uniform cutting energy that results in a better surface finish during the erosion process [50].

In this work, the obtained results of $R_{\mathrm{a}}$ are greater at thicknesses of 8 and $12 \mathrm{~mm}$, as compared to $4 \mathrm{~mm}$ AISI 304L. Additionally, the lowest $R_{\mathrm{a}}$ value was achieved by decreasing traverse speed to a rate of $90 \mathrm{~mm} / \mathrm{min}$. At the initial strike, the abrasive waterjet possesses high kinetic energy with vast number of abrasive particles which gradually decrease as the material thickness and traverse speed increases [51], resulting in an incremental value of surface roughness.

Table 6 displays the AISI 304L reaction for material removal rate (MRR) within the three levels of each selected input parameter in this study. The highest values of MRR were achieved in abrasive waterjet contour cutting of AISI $304 \mathrm{~L}$, with $421.2 \mathrm{~mm}^{3} / \mathrm{min}$ for $4 \mathrm{~mm}, 767.10 \mathrm{~mm}^{3} / \mathrm{min}$ for $8 \mathrm{~mm}$, and $811.4 \mathrm{~mm}^{3} / \mathrm{min}$ for $12 \mathrm{~mm}$ material thicknesses. Regardless of whether contour cutting covered an arc or a straight profile, higher material removal rates were attained via a high-level of abrasive mass flow rate and waterjet pressure. Increasing the waterjet pressure in conjunction with abrasive mass flow rate has been shown to improve material erosion, invoking a large amount of abrasives that result in lower surface roughness [22]. These results reveal an increasing MRR can be attained by incrementally increasing the level of traverse speed. An increasing traverse speed enhances the contact time of the waterjet with the abrasive on the target material, creating more volume of material to erode [22]. 
Table 6. The $\mathrm{L}_{27}$ orthogonal array of Taguchi for material removal rate results.

\begin{tabular}{|c|c|c|c|c|c|c|c|c|c|c|c|c|c|c|c|c|}
\hline \multirow{3}{*}{$\begin{array}{l}\text { Exp. } \\
\text { No. }\end{array}$} & \multicolumn{4}{|c|}{ Input Parameters } & \multicolumn{12}{|c|}{ Output Parameter $\left(\mathrm{MRR}=\mathrm{mm}^{3} / \mathrm{min}\right)$} \\
\hline & \multirow{2}{*}{$\begin{array}{c}t \\
(\mathrm{~mm})\end{array}$} & \multirow{2}{*}{$\begin{array}{c}V_{f} \\
(\mathrm{~mm} / \mathrm{min})\end{array}$} & \multirow{2}{*}{$\underset{(\mathrm{g} / \mathrm{min})}{\mathrm{m}_{\mathrm{a}}}$} & \multirow{2}{*}{$\begin{array}{c}P \\
\text { (MPa) }\end{array}$} & \multicolumn{12}{|c|}{ Profiles } \\
\hline & & & & & 1 & 2 & 3 & 4 & 5 & 6 & 7 & 8 & 9 & 10 & 11 & 12 \\
\hline 1 & 4 & 90 & 300 & 200 & 224.50 & 214.20 & 210.30 & 220.70 & 212.10 & 227.10 & 224.80 & 236.10 & 221.90 & 208.20 & 215.80 & 211.30 \\
\hline 2 & 4 & 90 & 400 & 250 & 225.60 & 225.30 & 211.30 & 234.30 & 223.10 & 248.60 & 246.10 & 258.40 & 242.90 & 209.20 & 236.20 & 231.30 \\
\hline 3 & 4 & 90 & 500 & 300 & 227.40 & 257.00 & 213.00 & 219.40 & 250.60 & 254.40 & 244.30 & 256.00 & 240.60 & 210.90 & 234.50 & 229.60 \\
\hline 4 & 4 & 120 & 300 & 250 & 351.10 & 335.10 & 328.90 & 348.50 & 331.70 & 355.20 & 351.60 & 369.20 & 347.00 & 325.60 & 337.50 & 330.50 \\
\hline 5 & 4 & 120 & 400 & 300 & 358.20 & 351.90 & 335.50 & 345.60 & 343.10 & 348.30 & 334.40 & 350.50 & 329.40 & 332.20 & 321.00 & 314.30 \\
\hline 6 & 4 & 120 & 500 & 200 & 353.60 & 377.50 & 331.20 & 388.80 & 373.70 & 400.10 & 396.10 & 415.90 & 391.00 & 327.90 & 380.30 & 372.30 \\
\hline 7 & 4 & 150 & 300 & 300 & 413.00 & 395.00 & 386.90 & 406.50 & 387.00 & 418.70 & 401.90 & 421.20 & 395.90 & 383.00 & 385.80 & 377.80 \\
\hline 8 & 4 & 150 & 400 & 200 & 403.40 & 390.00 & 377.80 & 401.70 & 386.10 & 404.00 & 400.00 & 420.00 & 394.80 & 374.10 & 384.00 & 376.00 \\
\hline 9 & 4 & 150 & 500 & 250 & 411.70 & 390.90 & 385.60 & 398.50 & 385.10 & 401.80 & 397.80 & 417.70 & 392.60 & 381.80 & 381.90 & 373.90 \\
\hline 10 & 8 & 90 & 300 & 200 & 383.40 & 365.90 & 359.20 & 376.90 & 362.30 & 387.90 & 384.00 & 403.20 & 379.00 & 355.60 & 368.70 & 361.00 \\
\hline 11 & 8 & 90 & 400 & 250 & 384.70 & 377.20 & 360.40 & 392.20 & 373.40 & 399.80 & 395.80 & 415.60 & 390.60 & 356.80 & 380.00 & 372.00 \\
\hline 12 & 8 & 90 & 500 & 300 & 381.10 & 403.80 & 357.00 & 367.70 & 393.70 & 399.70 & 383.70 & 402.20 & 378.00 & 353.50 & 368.40 & 360.70 \\
\hline 13 & 8 & 120 & 300 & 250 & 458.20 & 437.30 & 429.20 & 454.80 & 432.90 & 461.50 & 456.90 & 479.80 & 451.00 & 424.90 & 438.60 & 429.50 \\
\hline 14 & 8 & 120 & 400 & 300 & 467.40 & 456.10 & 437.80 & 450.90 & 444.70 & 451.50 & 433.40 & 454.20 & 427.00 & 433.40 & 416.10 & 407.40 \\
\hline 15 & 8 & 120 & 500 & 200 & 472.00 & 437.50 & 442.20 & 450.60 & 433.10 & 463.80 & 459.10 & 482.10 & 453.20 & 437.70 & 440.80 & 431.60 \\
\hline 16 & 8 & 150 & 300 & 300 & 656.00 & 626.10 & 614.50 & 632.90 & 610.40 & 619.80 & 595.00 & 623.60 & 586.20 & 608.30 & 571.20 & 559.30 \\
\hline 17 & 8 & 150 & 400 & 200 & 682.20 & 661.10 & 639.00 & 680.90 & 654.50 & 700.80 & 693.80 & 728.40 & 684.70 & 632.70 & 666.00 & 652.10 \\
\hline 18 & 8 & 150 & 500 & 250 & 687.50 & 696.20 & 644.00 & 724.00 & 689.20 & 737.90 & 730.60 & 767.10 & 721.10 & 637.60 & 701.30 & 686.70 \\
\hline 19 & 12 & 90 & 300 & 200 & 426.50 & 407.10 & 399.50 & 419.30 & 403.00 & 431.50 & 427.20 & 448.50 & 421.60 & 395.50 & 410.10 & 401.60 \\
\hline 20 & 12 & 90 & 400 & 250 & 428.60 & 419.10 & 401.50 & 435.90 & 414.90 & 444.20 & 439.80 & 461.80 & 434.10 & 397.50 & 422.20 & 413.40 \\
\hline 21 & 12 & 90 & 500 & 300 & 432.00 & 452.30 & 404.70 & 416.80 & 441.00 & 447.80 & 429.90 & 450.50 & 423.50 & 400.60 & 412.70 & 404.10 \\
\hline 22 & 12 & 120 & 300 & 250 & 667.00 & 636.60 & 624.80 & 662.10 & 630.20 & 674.80 & 668.10 & 701.50 & 659.40 & 618.60 & 641.30 & 628.00 \\
\hline 23 & 12 & 120 & 400 & 300 & 680.60 & 659.50 & 637.50 & 656.60 & 643.10 & 652.90 & 626.80 & 656.90 & 617.50 & 631.10 & 601.80 & 589.20 \\
\hline 24 & 12 & 120 & 500 & 200 & 671.80 & 631.20 & 629.30 & 650.10 & 624.90 & 669.00 & 662.30 & 695.50 & 653.70 & 623.00 & 635.90 & 622.60 \\
\hline 25 & 12 & 150 & 300 & 300 & 784.70 & 748.90 & 735.10 & 763.70 & 734.00 & 785.90 & 754.50 & 811.40 & 761.80 & 725.40 & 724.30 & 709.20 \\
\hline 26 & 12 & 150 & 400 & 200 & 766.40 & 741.40 & 717.90 & 757.10 & 730.20 & 740.50 & 733.10 & 769.70 & 723.50 & 710.70 & 703.70 & 689.10 \\
\hline 27 & 12 & 150 & 500 & 250 & 782.20 & 726.50 & 732.70 & 755.60 & 719.20 & 779.60 & 754.50 & 810.40 & 762.70 & 727.70 & 731.00 & 725.50 \\
\hline
\end{tabular}

Material removal rate $\mathrm{S} / \mathrm{N}$ ratios are presented in Table $\mathrm{A} 2$ of the Appendix A, where it is evident that with a material thickness of $4 \mathrm{~mm}$ the best combination of input parameters to achieve the highest MRR were $300 \mathrm{~g} / \mathrm{min}$ of abrasive flow rate $\left(\mathrm{m}_{\mathrm{a}}\right), 300 \mathrm{MPa}$ of waterjet pressure $(P)$ and $150 \mathrm{~mm} / \mathrm{min}$ of traverse speed $\left(V_{f}\right)$ for all types of profiles. This combination also achieved the highest MRR for $12 \mathrm{~mm}$ thickness, but only for cutting arc profiles. In AWJM of straight-line profiles for $12 \mathrm{~mm}$ AISI 304L, the best combination was $500 \mathrm{~g} / \mathrm{min}$ of $\mathrm{m}_{\mathrm{a}}, 250 \mathrm{MPa}$ of $P$ and $150 \mathrm{~mm} / \mathrm{min}$ of $V_{f}$. This combination was also found to generate the highest MRR for $8 \mathrm{~mm}$ thickness of the target workpiece.

According to the results obtained via ANOVA for surface roughness detailed in Table 7, material thickness emerges as the most influencing input parameter, followed by waterjet pressure and abrasive mass flow rate with a percent contribution ranging $90.72-97.74 \%$, $0.76-2.74 \%$ and $0.11-11 \%$, respectively for all profiles. This is in agreement with the topographical features shown in Figures 1-9. Waterjet pressure impacts the distribution of water and jet abrasive particles during erosion processes. Similarly, waterjet pressure alongside abrasive flow rate indicates comparable performance within AWJM. According to this statistical analysis, traverse speed provided the least contribution, where it was dominated by material thickness with a percentage contribution from $0.08 \%$ to $1.165 \%$. The effects of the parameters for all profiles demonstrate a similar trend, denoting that material thickness, waterjet pressure and abrasive mass flow rate are significant factors for acquiring $p$-values lower than 0.05 , as detailed in Table 7. Accordingly, this study has revealed traverse speed to be insignificant for achieving $p$-values $>0.05$, ranging from 0.090 to 0.575 .

In reference to results obtained from ANOVA for material removal rate that are presented in Table 8, waterjet pressure and abrasive mass flow rate provided the minimal effect on MRR, with a percentage ranging $7.88-12.65 \%$ and $0.2-1.45 \%$ accordingly. Material thickness featured in the ANOVA as the utmost impacting factor, followed by traverse speed with a percent contribution ranging $65.55-78.17 \%$ and $13.15-18.62 \%$, respectively for all profiles. The obtained $p$-values for material thickness, traverse speed and waterjet pressure were all less than 0.05, as illustrated in Table 8. Therefore, the influences of material thickness, waterjet pressure and traverse speed are all shown to be statistically significant. Contrastingly, abrasive mass flow rate achieved $p$-values ranging from 0.070 to 0.445 , indicating an insignificant factor affecting material removal rate. 
Table 7. Analysis of variance of surface roughness.

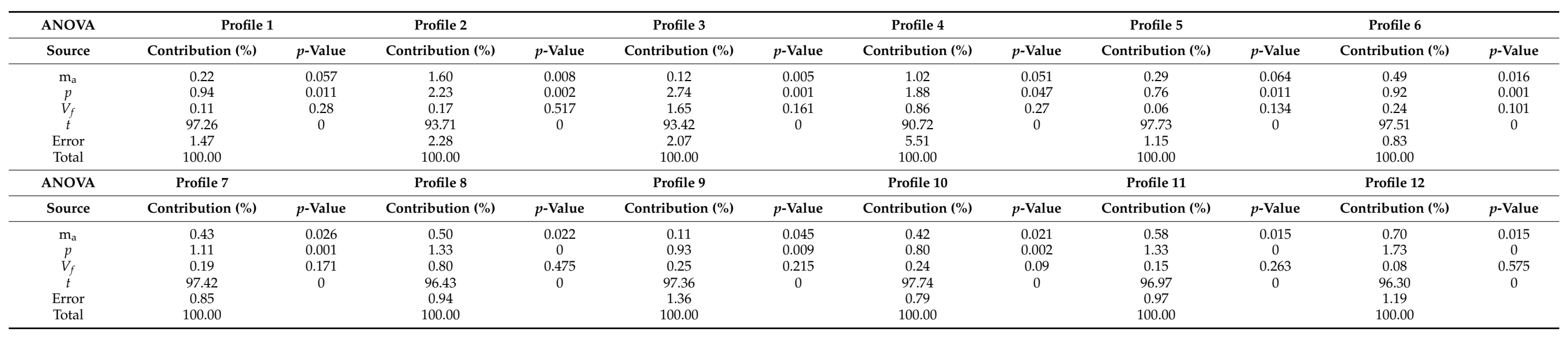

Table 8. Analysis of variance of material removal rate.

\begin{tabular}{|c|c|c|c|c|c|c|c|c|c|c|c|c|}
\hline \multirow{2}{*}{$\begin{array}{l}\text { ANOVA } \\
\text { Source }\end{array}$} & \multirow{2}{*}{$\begin{array}{c}\text { Profile } 1 \\
\text { Contribution (\%) }\end{array}$} & \multicolumn{3}{|c|}{ Profile 2} & \multirow{2}{*}{$\begin{array}{c}\text { Profile } 3 \\
\text { Contribution (\%) }\end{array}$} & \multicolumn{3}{|c|}{ Profile 4} & \multirow{2}{*}{$\begin{array}{c}\text { Profile } 5 \\
\text { Contribution (\%) }\end{array}$} & \multicolumn{3}{|c|}{ Profile 6} \\
\hline & & $p$-Value & Contribution (\%) & $p$-Value & & $p$-Value & Contribution (\%) & $p$-Value & & $p$-Value & Contribution (\%) & $p$-Value \\
\hline $\mathrm{m}_{\mathrm{a}}$ & 0.21 & 0.445 & 0.22 & 0.377 & 0.28 & 0.296 & 0.34 & 0.007 & 0.31 & 0.263 & 0.20 & 0.373 \\
\hline$p$ & 12.29 & 0 & 10.65 & 0.000 & 11.58 & 0.000 & 7.88 & 0.000 & 11.53 & 0.000 & 10.97 & 0.000 \\
\hline$V_{f}$ & 18.62 & 0 & 17.03 & 0.000 & 16.83 & 0.000 & 13.15 & 0.000 & 16.36 & 0.000 & 14.86 & 0.000 \\
\hline Error & 2.19 & & 1.95 & & 1.95 & & 0.46 & & 1.93 & & 1.76 & \\
\hline Total & 100.00 & & 100.00 & & 100.00 & & 100.00 & & 100.00 & & 100.00 & \\
\hline ANOVA & Profile 7 & & Profile 8 & & Profile 9 & & Profile 10 & & Profile 11 & & Profile 12 & \\
\hline Source & Contribution $(\%)$ & $p$-Value & Contribution (\%) & $p$-Value & Contribution (\%) & $p$-Value & Contribution (\%) & $p$-Value & Contribution (\%) & $p$-Value & Contribution (\%) & Source \\
\hline$p$ & 11.39 & 0.000 & 11.04 & 0.000 & 11.60 & 0.000 & 12.19 & 0.000 & 12.65 & 0.000 & 10.41 & 0.000 \\
\hline$V_{f}$ & 17.18 & 0.000 & 14.37 & 0.000 & 15.80 & 0.000 & 16.87 & 0.000 & 16.69 & 0.000 & 14.34 & 0.000 \\
\hline$t$ & 69.17 & 0.000 & 72.32 & 0.000 & 67.61 & 0.000 & 65.86 & 0.000 & 65.55 & 0.000 & 69.78 & 0.000 \\
\hline Error & 1.92 & & 1.96 & & 3.73 & & 3.63 & & 3.79 & & 4.15 & \\
\hline Total & 100.00 & & 100.00 & & 100.00 & & 100.00 & & 100.00 & & 100.00 & \\
\hline
\end{tabular}




\subsection{Optimisation with Taguchi S/N Ratio}

The average $\mathrm{S} / \mathrm{N}$ ratios shown in Table $\mathrm{A} 3$ in the Appendix A were attained from contour cutting of twelve different profiles with differing levels of selected input parameters. The lowest value of $\mathrm{S} / \mathrm{N}$ ratio obtained for each factor represents the best experimental result. These express similar results to Table A1, indicating the optimal combination of input parameters as Level 1 for traverse speed and Level 3 for abrasive mass flow rate and waterjet pressure, set at $90 \mathrm{~mm} / \mathrm{min}, 500 \mathrm{~g} / \mathrm{min}$ and $300 \mathrm{MPa}$ respectively. Table 9 summarizes the minimum value of surface roughness attained in abrasive waterjet contour cutting of AISI 304L, for three level material thicknesses for all profiles, according to the $\mathrm{L}_{27}$ orthogonal array experiment setup.

Table 9. Optimum parameters for surface roughness.

\begin{tabular}{|c|c|c|c|c|c|}
\hline Input Process Parameters & Optimum Values & Condition & \multicolumn{3}{|c|}{ Surface Roughness $(\mu \mathrm{m})$} \\
\hline Abrasive flow rate $(\mathrm{g} / \mathrm{min})$ & 500 & $\uparrow$ & \multicolumn{3}{|c|}{ Condition: minimised } \\
\hline Waterjet pressure (MPa) & 300 & $\uparrow$ & $t=4 \mathrm{~mm}$ & $t=8 \mathrm{~mm}$ & $t=12 \mathrm{~mm}$ \\
\hline Traverse speed (mm/min) & 90 & $\downarrow$ & 1.142 & 1.529 & 1.993 \\
\hline
\end{tabular}

The interaction of independent variables, i.e., material thickness $(t)$, abrasive flow rate $\left(\mathrm{m}_{\mathrm{a}}\right)$, waterjet pressure $(P)$, traverse speed $\left(V_{f}\right)$ on surface roughness $\left(R_{\mathrm{a}}\right)$ were indicated in the main effect plots shown in Figure 13. The main effect plots display the means for each profile within a particular variable. The surface roughness was shown to decrease by approximately $10-20 \%$ as the value of the waterjet pressure increases and the abrasive mass flow rate from $200 \mathrm{MPa}$ to $300 \mathrm{MPa}$ and $300 \mathrm{~g} / \mathrm{min}$ to $500 \mathrm{~g} / \mathrm{min}$, respectively. In AWJM, a higher level of waterjet pressure indicates an equivalent performance with abrasive mass flow rate [52]. An increasing water pressure along with the flow of abrasives, generates high velocity, resulting in a stronger impact of abrasive particles, which in turn decreases the roughness of the cut surface [53]. Hence, it is evident from the results of this study that increases in abrasive flow rate and waterjet pressure up until a particular level enhances the smoothening of cut surfaces.

Moreover, increasing the rate of traverse speed and thickness of a material increases the value of surface roughness. Surface roughness in this study was established to increase by approximately $50-60 \%$ as the level of material thickness and traverse speed increases from $4 \mathrm{~mm}$ to $12 \mathrm{~mm}$ and from $90 \mathrm{~mm} / \mathrm{min}$ to $150 \mathrm{~mm} / \mathrm{min}$, respectively. The abrasive particles containing high kinetic energy occur at the initial strike and gradually decrease during the machining process [51]. Accordingly, reduced amounts of collision and cutting edges can be obtainable per unit of area over time, resulting in higher incidences of rough surfaces. Hence, it can be predicted that a lower level of traverse speed can yield a better-machined surface. Further, an increasing speed and thickness of a material denotes prolongment of the machining process, which continuously reduces the kinetic energy and generates higher roughness of a cut surface.

In the Taguchi method, the obtained $\mathrm{S} / \mathrm{N}$ ratios are averaged to configure the optimum combination of parameters applicable for all conditions or profiles. Table A4 in the Appendix A presents the average $\mathrm{S} / \mathrm{N}$ ratios calculated for each profile with different levels of input parameters, denoting that a traverse speed at level 3 , an abrasive mass flow rate at level 3 and pressure at level 3 are the optimal combination of input parameters. Table 10 summarizes the optimum values input parameters and material removal rate obtained in abrasive waterjet contour cutting of AISI 304L, according to average S/N Ratios and the $\mathrm{L}_{27}$ orthogonal array experiment setup.

The nomination of the optimal level of each input parameter is further evidenced by the main effect plots. Figure 14 shows the main effect plots for means in abrasive waterjet contour cutting of AISI 304L in terms of maximizing MRR. The figure shows that an increasing level of material thickness and traverse speed denotes an improvement of the rate of material removal for all profiles. 

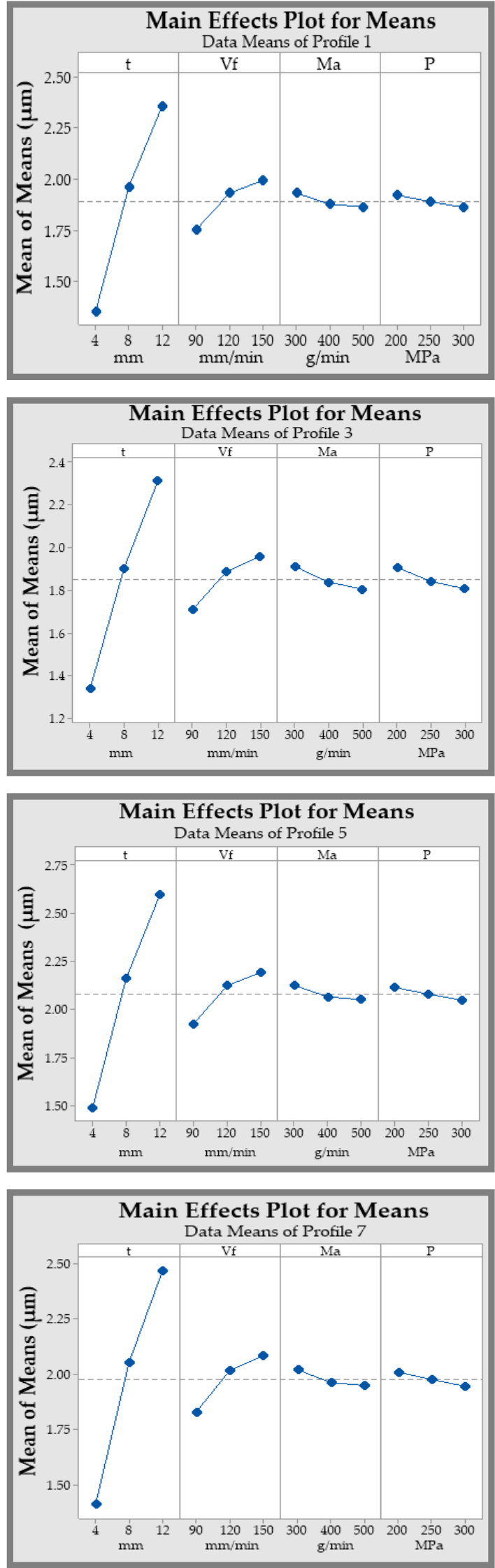
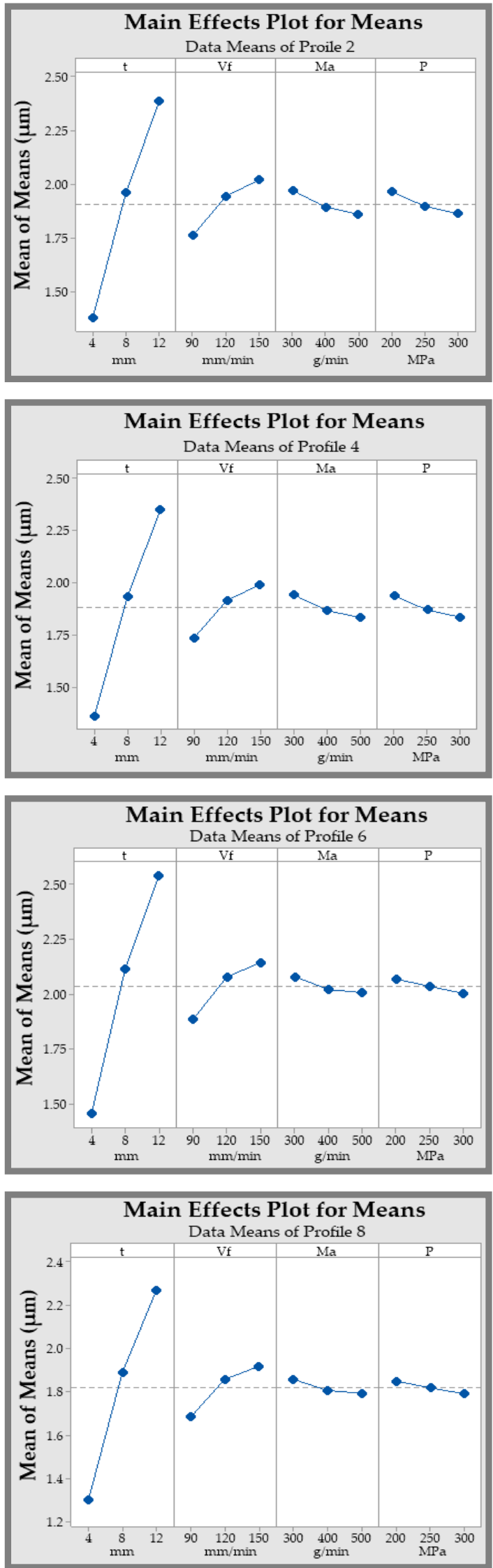

Figure 13. Cont. 

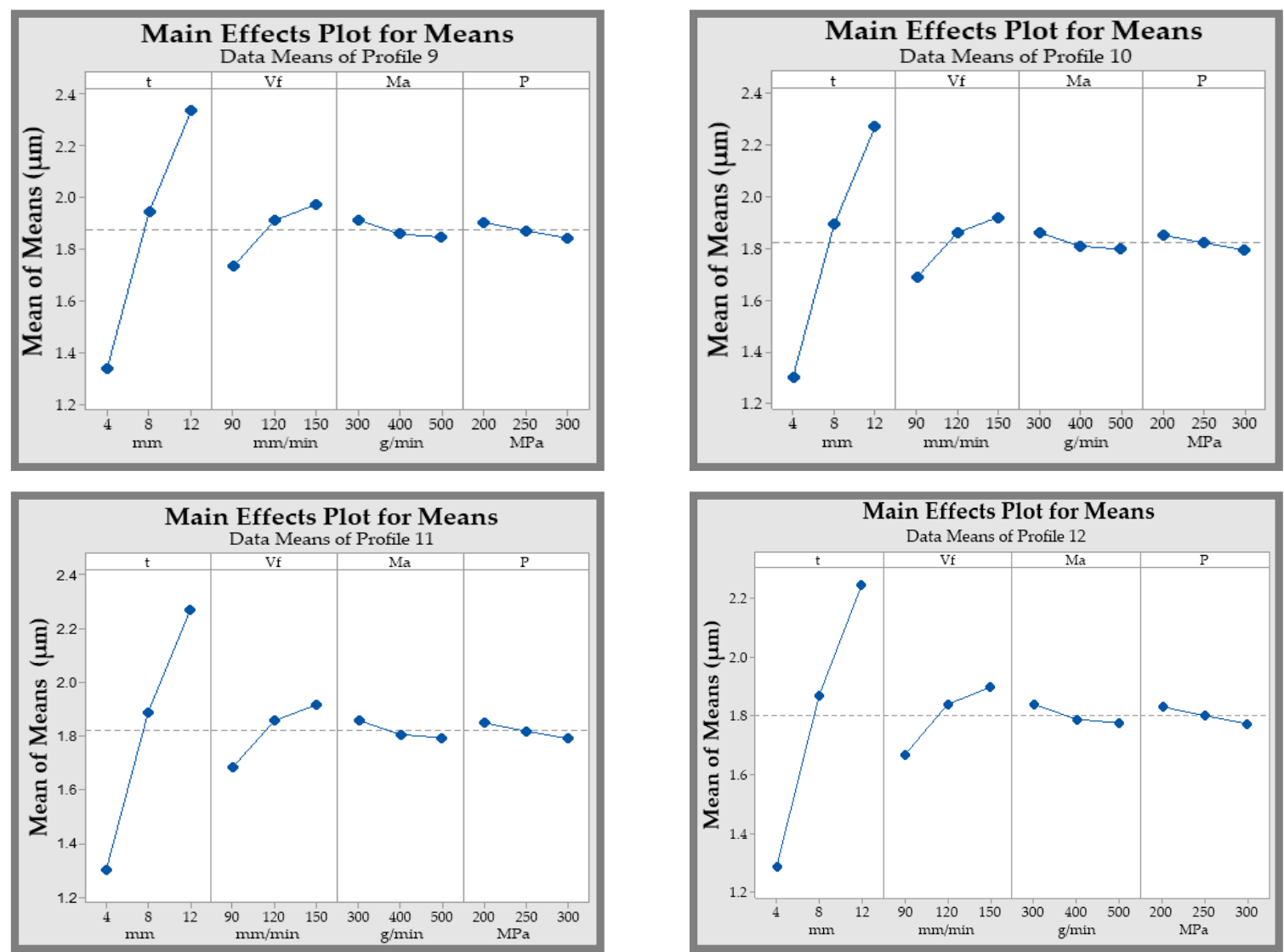

Figure 13. Main effect plot of means of surface roughness against input parameters.

Table 10. Optimum parameters for material removal rate.

\begin{tabular}{cccccc}
\hline Input Process Parameters & Optimum Values & Condition & \multicolumn{3}{c}{$\begin{array}{c}\text { Material Removal Rate } \\
\left(\mathbf{m m}^{3} / \mathbf{m i n}\right)\end{array}$} \\
\hline Abrasive flow rate $(\mathrm{g} / \mathrm{min})$ & 500 & $\uparrow$ & \multicolumn{3}{c}{ Condition: maximised } \\
Waterjet pressure $(\mathrm{MPa})$ & 300 & $\uparrow$ & $t=4 \mathrm{~mm}$ & $t=8 \mathrm{~mm}$ & $t=12 \mathrm{~mm}$ \\
Traverse speed $(\mathrm{mm} / \mathrm{min})$ & 150 & $\uparrow$ & 421.2 & 767.1 & 811.4 \\
\hline
\end{tabular}

The material removal rate was shown to increase by approximately $70 \%$ when higher values of material thickness and traverse speed are used. AWJM is primarily processed by cohering action generated from the impacts of a large amount of abrasive particles in the direction of the target material [51]. In addition, material removal rate is directly proportional to abrasive mass flow rate and waterjet pressure. An increase of approximately $70 \%$ of material removal rate was obtained as the rate of abrasive mass flow rate and waterjet pressure were increased from $200 \mathrm{MPa}$ to $300 \mathrm{MPa}$ and $300 \mathrm{~g} / \mathrm{min}$ to $500 \mathrm{~g} / \mathrm{min}$, respectively. AWJM of ductile material, such as AISI 304L, occurs via erosion generated by impinging abrasive particles from the waterjet stream. Generation of a high level of kinetic energy relating to a higher level of waterjet pressure generates higher erosion or cutting rate leading to a larger amount of material eroded from the workpiece [22]. Therefore, the rate of material removal is highly dictated by waterjet pressure and abrasive mass flow rate. 

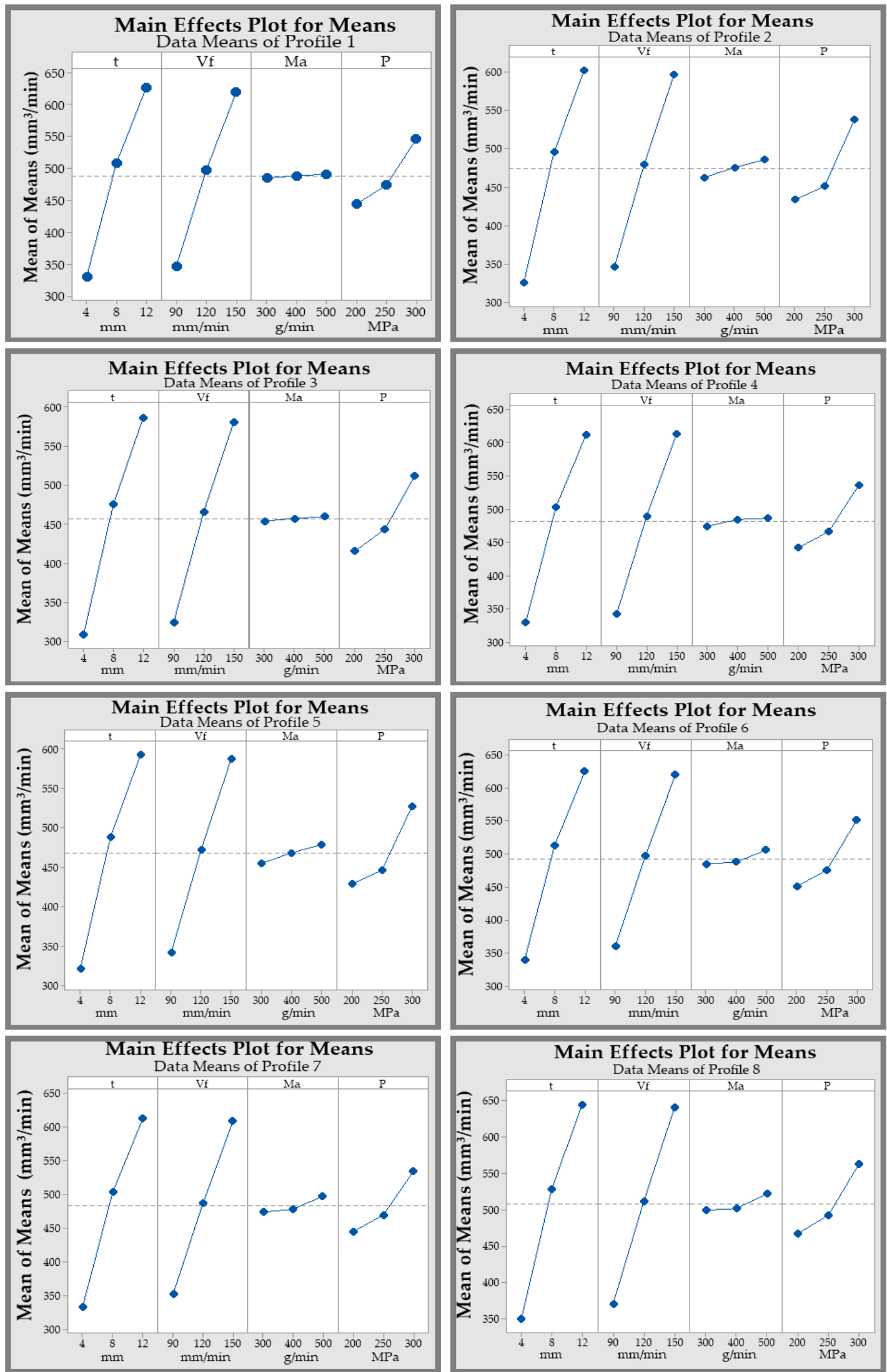

Figure 14. Cont. 

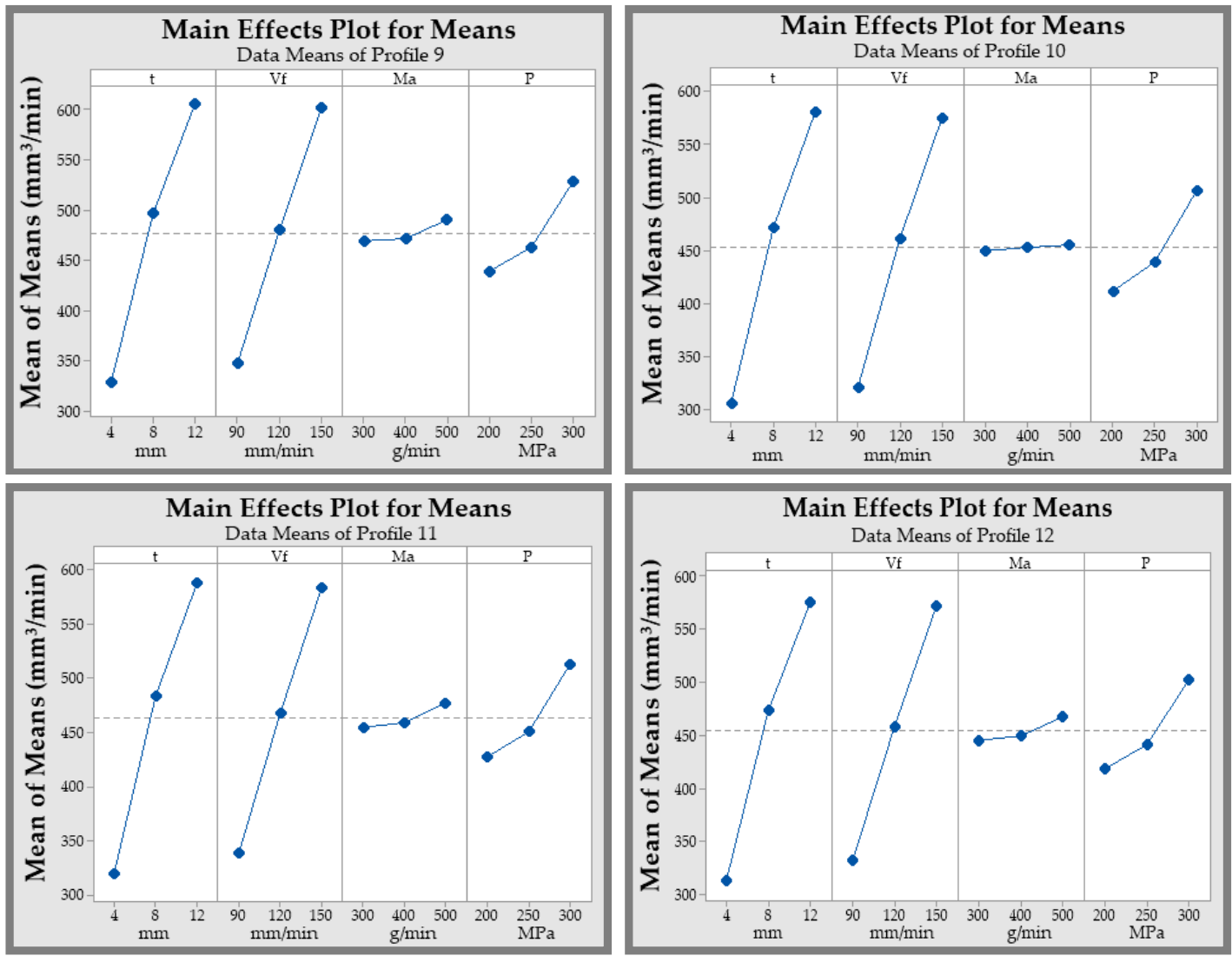

Figure 14. Main effect plot of means for material removal rate against input parameters.

\section{Confirmation Test}

Validation of the optimal process parameters via a combination derived from the Taguchi methodology was established by confirmation experiments. Three sets of confirmatory test run for abrasive waterjet contour cutting of AISI 304L were conducted utilizing the derived optimal levels of traverse speed, abrasive mass flow rate and waterjet pressure based on the average $\mathrm{S} / \mathrm{N}$ ratio.

The parametric combination of $V_{f}$ at level $1(90 \mathrm{~mm} / \mathrm{min}), \mathrm{m}_{\mathrm{a}}$ at level $3(500 \mathrm{~g} / \mathrm{min})$ and $P$ at level $3\left(300 \mathrm{MPa}\right.$ ) achieved $R_{\mathrm{a}}$ values of $1.133 \mu \mathrm{m}$ for $4 \mathrm{~mm}, 1.372 \mu \mathrm{m}$ for $8 \mathrm{~mm}$, and $1.901 \mu \mathrm{m}$ for $12 \mathrm{~mm}$ material thicknesses, demonstrating relative values to results achieved from the $\mathrm{L}_{27}$ orthogonal array experiment setup.

The derived optimal process parameter mix obtained to achieve maximum material removal rate was $V_{f}$ at Level $3(150 \mathrm{~mm} / \mathrm{min}), \mathrm{m}_{\mathrm{a}}$ at Level $3(500 \mathrm{~g} / \mathrm{min})$ and $P$ at Level 3 (300 MPa) attaining MRR values of $425.4 \mathrm{~mm}^{3} / \mathrm{min}$ for $4 \mathrm{~mm}, 751.6 \mathrm{~mm}^{3} / \mathrm{min}$ for $8 \mathrm{~mm}$, and $809.7 \mathrm{~mm}^{3} / \mathrm{min}$ for $12 \mathrm{~mm}$ material thicknesses.

\section{Conclusions}

This article presents an optimization of abrasive waterjet contour cutting process parameters to minimize surface roughness and maximize material removal rate. In addition, the impacts of material thickness, traverse speed, waterjet pressure and abrasive mass flow rate were investigated, facilitating the process to achieve better surface integrity and machining rates. On the basis of Taguchi-based optimization and analysis of variance, the following conclusions were acquired: 
- A minimum value of surface roughness achieved, where $1.142 \mu \mathrm{m}$ for $4 \mathrm{~mm}, 1.529 \mu \mathrm{m}$ for $8 \mathrm{~mm}$, and $1.993 \mu \mathrm{m}$ for $12 \mathrm{~mm}$ material thicknesses according to $\mathrm{L}_{27}$ orthogonal array experiment setup. The average $\mathrm{S} / \mathrm{N}$ ratios expressed similar results to all profiles, indicating the optimal combination of input parameters of Level 1 for traverse speed, Level 3 for abrasive mass flow rate and waterjet pressure at $90 \mathrm{~mm} / \mathrm{min}, 500 \mathrm{~g} / \mathrm{min}$ and $300 \mathrm{MPa}$ respectively.

- The optimal settings observed for increasing material removal rate are traverse speed at Level 3 (150 $\mathrm{mm} / \mathrm{min})$, abrasive mass flow rate at Level 3 (500 g/min) and pressure at Level 3 (300 MPa). Increasing the value of these selected parameters was found to increase material thickness by approximately $70 \%$.

- $\quad$ By employing analysis of variance, material thickness features as the most influencing and significant factor in governing responses on surface roughness and material removal rate, generating a contribution ranging $90.72-97.74 \%$ and $65.55-78.17 \%$ for all profiles, respectively.

- An increasing level of waterjet pressure and abrasive mass flow rate denotes an improvement in contour cutting performance by decreasing the surface roughness. In contrast, an increasing speed of traverse and material thickness drives a negative impact, whereby it increases the roughness of the cut surface.

Author Contributions: Conceptualization and methodology: M.T.-R., A.V., J.M.L. and M.A.; investigation and writing original draft: J.M.L.; review and supervision: M.T.-R., A.V., J.M.L. and M.A.; editing, project administration and software application: J.M.L. and M.A. All authors have read and agreed to the published version of the manuscript.

Funding: This research received an open access funding from School of Engineering, Edith Cowan University, Australia.

Institutional Review Board Statement: Not applicable.

Informed Consent Statement: Not applicable.

Data Availability Statement: Not applicable.

Acknowledgments: The authors would like to thank the School of Engineering, Edith Cowan University, Australia, for providing and administering the needed requirements in accomplishing this research. The authors would like to thank the technical staff, Adrian Davis for his assistance in experiments and Michael Stein for his assistance in writing structure and proficiency.

Conflicts of Interest: The authors declare no conflict of interest.

\section{Abbreviations and Nomenclature}

$\begin{array}{ll}h t & \text { Depth of cut } \\ \mathrm{m}_{\mathrm{a}} & \text { Abrasive mass flow rate } \\ P & \text { Water pressure } \\ R_{\mathrm{a}} & \text { Surface roughness } \\ V_{f} & \text { Traverse speed } \\ W & \text { Kerf width } \\ W_{t} & \text { Kerf top width } \\ W_{b} & \text { Kerf bottom width } \\ t & \text { Thickness of the material } \\ \text { AISI } & \text { Austenitic stainless steel } \\ \text { ANOVA } & \text { Analysis of variance } \\ \text { AWJM } & \text { Abrasive waterjet machining } \\ \text { MRR } & \text { Material removal rate }\end{array}$




\section{Appendix A}

Table A1. Signal-to-noise ratios for surface roughness (smaller is better).

\begin{tabular}{|c|c|c|c|c|c|c|c|c|c|c|c|c|c|c|c|c|}
\hline \multirow{3}{*}{$\begin{array}{l}\text { Exp. } \\
\text { No. }\end{array}$} & \multicolumn{4}{|c|}{ Input Parameters } & \multicolumn{12}{|c|}{ Signal to Noise Ratios $(\mathrm{S} / \mathrm{NR}=\mathrm{dB})$} \\
\hline & \multirow{2}{*}{$\begin{array}{c}t \\
(\mathrm{~mm})\end{array}$} & \multirow{2}{*}{$\begin{array}{c}V_{f} \\
(\mathrm{~mm} / \mathrm{min})\end{array}$} & \multirow{2}{*}{$\underset{(\mathrm{g} / \mathrm{min})}{\mathrm{m}_{\mathrm{a}}}$} & \multirow{2}{*}{$\begin{array}{c}P \\
(\mathrm{MPa})\end{array}$} & \multicolumn{12}{|c|}{ Profiles } \\
\hline & & & & & 1 & 2 & 3 & 4 & 5 & 6 & 7 & 8 & 9 & 10 & 11 & 12 \\
\hline 1 & 4 & 90 & 300 & 200 & -2.265 & -2.437 & -2.173 & -2.312 & -3.093 & -2.900 & -2.648 & -1.924 & -2.178 & -1.938 & -1.924 & -1.836 \\
\hline 2 & 4 & 90 & 400 & 250 & -1.980 & -2.152 & -1.887 & -2.026 & -2.808 & -2.614 & -2.362 & -1.638 & -1.892 & -1.652 & -1.638 & -1.551 \\
\hline 3 & 4 & 90 & 500 & 300 & -1.584 & -1.613 & -1.348 & -1.487 & -2.411 & -2.218 & -1.966 & -1.242 & -1.496 & -1.256 & -1.242 & -1.154 \\
\hline 4 & 4 & 120 & 300 & 250 & -2.910 & -3.082 & -2.818 & -2.956 & -3.738 & -3.545 & -3.292 & -2.568 & -2.823 & -2.583 & -2.568 & -2.481 \\
\hline 5 & 4 & 120 & 400 & 300 & -2.574 & -2.746 & -2.482 & -2.62 & -3.402 & -3.209 & -2.957 & -2.233 & -2.487 & -2.247 & -2.233 & -2.145 \\
\hline 6 & 4 & 120 & 500 & 200 & -2.916 & -3.335 & -3.070 & -3.209 & -3.744 & -3.551 & -3.299 & -2.574 & -2.829 & -2.589 & -2.574 & -2.487 \\
\hline 7 & 4 & 150 & 300 & 300 & -3.215 & -3.387 & -3.123 & -3.261 & -4.043 & -3.850 & -3.598 & -2.873 & -3.128 & -2.888 & -2.873 & -2.786 \\
\hline 8 & 4 & 150 & 400 & 200 & -3.082 & -3.254 & -2.990 & -3.128 & -3.910 & -3.717 & -3.465 & -2.740 & -2.995 & -2.755 & -2.740 & -2.653 \\
\hline 9 & 4 & 150 & 500 & 250 & -2.929 & -2.978 & -2.714 & -2.852 & -3.757 & -3.563 & -3.311 & -2.587 & -2.841 & -2.601 & -2.587 & -2.500 \\
\hline 10 & 8 & 90 & 300 & 200 & -5.511 & -5.683 & -5.418 & -5.557 & -6.339 & -6.145 & -5.893 & -5.169 & -5.424 & -5.183 & -5.169 & -5.082 \\
\hline 11 & 8 & 90 & 400 & 250 & -5.225 & -5.397 & -5.133 & -5.271 & -6.053 & -5.860 & -5.607 & -4.883 & -5.138 & -4.898 & -4.883 & -4.796 \\
\hline 12 & 8 & 90 & 500 & 300 & -4.829 & -3.951 & -3.687 & -3.825 & -5.657 & -5.464 & -5.211 & -4.487 & -4.742 & -4.502 & -4.487 & -4.400 \\
\hline 13 & 8 & 120 & 300 & 250 & -6.155 & -6.327 & -6.063 & -6.201 & -6.983 & -6.790 & -6.538 & -5.814 & -6.068 & -5.828 & -5.814 & -5.726 \\
\hline 14 & 8 & 120 & 400 & 300 & -5.820 & -5.543 & -5.278 & -5.417 & -6.648 & -6.454 & -6.202 & -5.478 & -5.732 & -5.492 & -5.478 & -5.391 \\
\hline 15 & 8 & 120 & 500 & 200 & -6.162 & -6.334 & -6.069 & -6.208 & -6.99 & -6.796 & -6.544 & -5.820 & -6.074 & -5.834 & -5.820 & -5.732 \\
\hline 16 & 8 & 150 & 300 & 300 & -6.461 & -6.633 & -6.368 & -6.507 & -7.289 & -7.095 & -6.843 & -6.119 & -6.373 & -6.133 & -6.119 & -6.031 \\
\hline 17 & 8 & 150 & 400 & 200 & -6.328 & -6.500 & -6.235 & -6.374 & -7.156 & -6.962 & -6.710 & -5.986 & -6.240 & -6.000 & -5.986 & -5.898 \\
\hline 18 & 8 & 150 & 500 & 250 & -6.174 & -6.012 & -5.747 & -5.886 & -7.002 & -6.809 & -6.556 & -5.832 & -6.087 & -5.847 & -5.832 & -5.745 \\
\hline 19 & 12 & 90 & 300 & 200 & -7.102 & -7.274 & -7.009 & -7.148 & -7.930 & -7.736 & -7.484 & -6.760 & -7.014 & -6.774 & -6.760 & -6.672 \\
\hline 20 & 12 & 90 & 400 & 250 & -6.816 & -6.988 & -6.723 & -6.862 & -7.644 & -7.451 & -7.198 & -6.474 & -6.729 & -6.489 & -6.474 & -6.387 \\
\hline 21 & 12 & 90 & 500 & 300 & -6.420 & -6.592 & -6.327 & -6.466 & -7.248 & -7.054 & -6.802 & -6.078 & -6.333 & -6.092 & -6.078 & -5.991 \\
\hline 22 & 12 & 120 & 300 & 250 & -7.746 & -7.633 & -7.369 & -7.507 & -8.574 & -8.381 & -8.129 & -7.404 & -7.659 & -7.419 & -7.404 & -7.317 \\
\hline 23 & 12 & 120 & 400 & 300 & -7.411 & -7.265 & -7.000 & -7.139 & -8.238 & -8.045 & -7.793 & -7.069 & -7.323 & -7.083 & -7.069 & -6.981 \\
\hline 24 & 12 & 120 & 500 & 200 & -7.753 & -7.925 & -7.660 & -7.799 & -8.58 & -8.387 & -8.135 & -7.411 & -7.665 & -7.425 & -7.411 & -7.323 \\
\hline 25 & 12 & 150 & 300 & 300 & -8.052 & -8.491 & -8.227 & -8.365 & -8.879 & -8.686 & -8.434 & -7.710 & -7.964 & -7.724 & -7.710 & -7.622 \\
\hline 26 & 12 & 150 & 400 & 200 & -7.919 & -8.091 & -7.826 & -7.965 & -8.746 & -8.553 & -8.301 & -7.577 & -7.831 & -7.591 & -7.577 & -7.489 \\
\hline 27 & 12 & 150 & 500 & 250 & -7.765 & -7.579 & -7.314 & -7.453 & -8.593 & -8.400 & -8.147 & -7.423 & -7.678 & -7.438 & -7.423 & -7.336 \\
\hline
\end{tabular}

Table A2. Signal-to-noise ratios for material removal rate (larger is better).

\begin{tabular}{|c|c|c|c|c|c|c|c|c|c|c|c|c|c|c|c|c|}
\hline \multirow{3}{*}{$\begin{array}{l}\text { Exp. } \\
\text { No. }\end{array}$} & \multicolumn{4}{|c|}{ Input Parameters } & \multicolumn{12}{|c|}{ Signal to Noise Ratios $(\mathrm{S} / \mathrm{NR}=\mathrm{dB})$} \\
\hline & \multirow{2}{*}{$\begin{array}{c}t \\
(\mathrm{~mm})\end{array}$} & \multirow{2}{*}{$\begin{array}{c}V_{f} \\
(\mathrm{~mm} / \mathrm{min})\end{array}$} & \multirow{2}{*}{$\underset{(\mathrm{g} / \mathrm{min})}{\mathrm{m}_{\mathrm{a}}}$} & \multirow{2}{*}{$P(\mathrm{MPa})$} & \multicolumn{12}{|c|}{ Profiles } \\
\hline & & & & & 1 & 2 & 3 & 4 & 5 & 6 & 7 & 8 & 9 & 10 & 11 & 12 \\
\hline 1 & 4 & 90 & 300 & 200 & 47.00 & 46.60 & 46.50 & 46.90 & 46.50 & 47.10 & 47.00 & 47.50 & 46.90 & 46.40 & 46.70 & 46.50 \\
\hline 2 & 4 & 90 & 400 & 250 & 47.10 & 47.10 & 46.50 & 47.40 & 47.00 & 47.90 & 47.80 & 48.20 & 47.70 & 46.40 & 47.50 & 47.30 \\
\hline 3 & 4 & 90 & 500 & 300 & 47.10 & 48.20 & 46.60 & 46.80 & 48.00 & 48.10 & 47.80 & 48.20 & 47.60 & 46.50 & 47.40 & 47.20 \\
\hline 4 & 4 & 120 & 300 & 250 & 50.90 & 50.50 & 50.30 & 50.80 & 50.40 & 51.00 & 50.90 & 51.30 & 50.80 & 50.30 & 50.60 & 50.40 \\
\hline 5 & 4 & 120 & 400 & 300 & 51.10 & 50.90 & 50.50 & 50.80 & 50.70 & 50.80 & 50.50 & 50.90 & 50.40 & 50.40 & 50.10 & 49.90 \\
\hline 6 & 4 & 120 & 500 & 200 & 51.00 & 51.50 & 50.40 & 51.80 & 51.50 & 52.00 & 52.00 & 52.40 & 51.80 & 50.30 & 51.60 & 51.40 \\
\hline 7 & 4 & 150 & 300 & 300 & 52.30 & 51.90 & 51.80 & 52.20 & 51.80 & 52.40 & 52.10 & 52.50 & 52.00 & 51.70 & 51.70 & 51.50 \\
\hline 8 & 4 & 150 & 400 & 200 & 52.10 & 51.80 & 51.50 & 52.10 & 51.70 & 52.10 & 52.00 & 52.50 & 51.90 & 51.50 & 51.70 & 51.50 \\
\hline 9 & 4 & 150 & 500 & 250 & 52.30 & 51.80 & 51.70 & 52.00 & 51.70 & 52.10 & 52.00 & 52.40 & 51.90 & 51.60 & 51.60 & 51.50 \\
\hline 10 & 8 & 90 & 300 & 200 & 51.70 & 51.30 & 51.10 & 51.50 & 51.20 & 51.80 & 51.70 & 52.10 & 51.60 & 51.00 & 51.30 & 51.10 \\
\hline 11 & 8 & 90 & 400 & 250 & 51.70 & 51.50 & 51.10 & 51.90 & 51.40 & 52.00 & 51.90 & 52.40 & 51.80 & 51.00 & 51.60 & 51.40 \\
\hline 12 & 8 & 90 & 500 & 300 & 51.60 & 52.10 & 51.10 & 51.30 & 51.90 & 52.00 & 51.70 & 52.10 & 51.60 & 51.00 & 51.30 & 51.10 \\
\hline 13 & 8 & 120 & 300 & 250 & 53.20 & 52.80 & 52.70 & 53.20 & 52.70 & 53.30 & 53.20 & 53.60 & 53.10 & 52.60 & 52.80 & 52.70 \\
\hline 14 & 8 & 120 & 400 & 300 & 53.40 & 53.20 & 52.80 & 53.10 & 53.00 & 53.10 & 52.70 & 53.10 & 52.60 & 52.70 & 52.40 & 52.20 \\
\hline 15 & 8 & 120 & 500 & 200 & 53.50 & 52.80 & 52.90 & 53.10 & 52.70 & 53.30 & 53.20 & 53.70 & 53.10 & 52.80 & 52.90 & 52.70 \\
\hline 16 & 8 & 150 & 300 & 300 & 56.30 & 55.90 & 55.80 & 56.00 & 55.70 & 55.80 & 55.50 & 55.90 & 55.40 & 55.70 & 55.10 & 55.00 \\
\hline 17 & 8 & 150 & 400 & 200 & 56.70 & 56.40 & 56.10 & 56.70 & 56.30 & 56.90 & 56.80 & 57.20 & 56.70 & 56.00 & 56.50 & 56.30 \\
\hline 18 & 8 & 150 & 500 & 250 & 56.70 & 56.90 & 56.20 & 57.20 & 56.80 & 57.40 & 57.30 & 57.70 & 57.20 & 56.10 & 56.90 & 56.70 \\
\hline 19 & 12 & 90 & 300 & 200 & 52.60 & 52.20 & 52.00 & 52.50 & 52.10 & 52.70 & 52.60 & 53.00 & 52.50 & 51.90 & 52.30 & 52.10 \\
\hline 20 & 12 & 90 & 400 & 250 & 52.60 & 52.40 & 52.10 & 52.80 & 52.40 & 53.00 & 52.90 & 53.30 & 52.80 & 52.00 & 52.50 & 52.30 \\
\hline 21 & 12 & 90 & 500 & 300 & 52.70 & 53.10 & 52.10 & 52.40 & 52.90 & 53.00 & 52.70 & 53.10 & 52.50 & 52.10 & 52.30 & 52.10 \\
\hline 22 & 12 & 120 & 300 & 250 & 56.50 & 56.10 & 55.90 & 56.40 & 56.00 & 56.60 & 56.50 & 56.90 & 56.40 & 55.80 & 56.10 & 56.00 \\
\hline 23 & 12 & 120 & 400 & 300 & 56.70 & 56.40 & 56.10 & 56.30 & 56.20 & 56.30 & 55.90 & 56.40 & 55.80 & 56.00 & 55.60 & 55.40 \\
\hline 24 & 12 & 120 & 500 & 200 & 56.50 & 56.00 & 56.00 & 56.30 & 55.90 & 56.50 & 56.40 & 56.80 & 56.30 & 55.90 & 56.10 & 55.90 \\
\hline 25 & 12 & 150 & 300 & 300 & 57.90 & 57.50 & 57.30 & 57.70 & 57.30 & 57.90 & 57.60 & 58.20 & 57.60 & 57.20 & 57.20 & 57.00 \\
\hline 26 & 12 & 150 & 400 & 200 & 57.70 & 57.40 & 57.10 & 57.60 & 57.30 & 57.40 & 57.30 & 57.70 & 57.20 & 57.00 & 56.90 & 56.80 \\
\hline 27 & 12 & 150 & 500 & 250 & 57.90 & 57.20 & 57.30 & 57.60 & 57.10 & 57.80 & 57.60 & 58.20 & 57.60 & 57.20 & 57.40 & 57.20 \\
\hline
\end{tabular}


Table A3. Average response table for signal-to-noise ratios for surface roughness (smaller is better).

\begin{tabular}{|c|c|c|c|c|c|c|c|c|c|c|c|c|c|c|c|c|}
\hline \multicolumn{5}{|c|}{ Profile 1} & \multicolumn{4}{|c|}{ Profile 2} & \multicolumn{4}{|c|}{ Profile 3} & \multicolumn{4}{|c|}{ Profile 4} \\
\hline Level & $t$ & $V_{f}$ & $\mathrm{~m}_{\mathrm{a}}$ & $P$ & $t$ & $V_{f}$ & $\mathrm{~m}_{\mathrm{a}}$ & $P$ & $t$ & $V_{f}$ & $\mathrm{~m}_{\mathrm{a}}$ & $P$ & $t$ & $V_{f}$ & $\mathrm{~m}_{\mathrm{a}}$ & $P$ \\
\hline 1 & -2.606 & -4.637 & -5.491 & -5.449 & -2.776 & -4.676 & -5.661 & -5.648 & -2.512 & -4.412 & -5.396 & -5.383 & -2.650 & -4.550 & -5.535 & -5.522 \\
\hline 2 & -5.852 & -5.494 & -5.239 & -5.300 & -5.820 & -5.577 & -5.326 & -5.350 & -5.555 & -5.312 & -5.062 & -5.085 & -5.694 & -5.451 & -5.200 & -5.224 \\
\hline 3 & -7.442 & -5.769 & -5.170 & -5.152 & -7.537 & -5.881 & -5.146 & -5.136 & -7.273 & -5.616 & -4.882 & -4.871 & -7.411 & -5.755 & -5.020 & -5.010 \\
\hline Delta & 4.836 & 1.133 & 0.321 & 0.297 & 4.761 & 1.204 & 0.515 & 0.512 & 4.761 & 1.204 & 0.515 & 0.512 & 4.761 & 1.204 & 0.515 & 0.512 \\
\hline Rank & 1 & 2 & 3 & 4 & 1 & 2 & 3 & 4 & 1 & 2 & 3 & 4 & 1 & 2 & 3 & 4 \\
\hline \multicolumn{5}{|c|}{ Profile 5} & \multicolumn{4}{|c|}{ Profile 6} & \multicolumn{4}{|c|}{ Profile 7} & \multicolumn{4}{|c|}{ Profile 8} \\
\hline Level & $t$ & $V_{f}$ & $\mathbf{m}_{\mathbf{a}}$ & $P$ & $t$ & $V_{f}$ & $\mathbf{m}_{\mathrm{a}}$ & $P$ & $t$ & $V_{f}$ & $\mathrm{~m}_{\mathrm{a}}$ & $P$ & $t$ & $V_{f}$ & $\mathrm{~m}_{\mathrm{a}}$ & $P$ \\
\hline 1 & -3.434 & 5.465 & -6.319 & -6.276 & - & -5.271 & -6.125 & -6 & -2.989 & -5.019 & -5.873 & -5 & -2 & -4.295 & -5.149 & -5.107 \\
\hline 2 & -6.679 & -6.322 & -6.067 & -6.128 & -6.486 & -6.129 & -5.874 & -5.935 & -6.234 & -5.876 & -5.622 & -5.682 & -5.510 & -5.152 & -4.897 & -4.958 \\
\hline 3 & -8.270 & -6.597 & -5.998 & -5.979 & -8.077 & -6.404 & -5.805 & -5.786 & -7.825 & -6.152 & -5.552 & -5.534 & -7.101 & -5.427 & -4.828 & -4.810 \\
\hline Delta & 4.836 & 1.133 & 0.321 & 0.297 & 4.836 & 1.133 & 0.321 & 0.297 & 4.836 & 1.133 & 0.321 & 0.297 & 4.836 & 1.133 & 0.321 & 0.297 \\
\hline Rank & 1 & 2 & 3 & 4 & 1 & 2 & 3 & 4 & 1 & 2 & 3 & 4 & 1 & 2 & 3 & 4 \\
\hline \multicolumn{5}{|c|}{ Profile 9} & \multicolumn{4}{|c|}{ Profile 10} & \multicolumn{4}{|c|}{ Profile 11} & \multicolumn{4}{|c|}{ Profile 12} \\
\hline Level & $t$ & $V_{f}$ & $\mathrm{~m}_{\mathrm{a}}$ & $P$ & $t$ & $V_{f}$ & $\mathrm{~m}_{\mathrm{a}}$ & $P$ & $t$ & $V_{f}$ & $\mathrm{~m}_{\mathrm{a}}$ & $P$ & $t$ & $V_{f}$ & $\mathrm{~m}_{\mathrm{a}}$ & $P$ \\
\hline 1 & -2.519 & -4.550 & -5.404 & -5.361 & -2.264 & -4.295 & -5.149 & -5.107 & -2.177 & -4.208 & -5.062 & -5.019 & -2.279 & -4.309 & -5.164 & -5.121 \\
\hline 2 & -5.764 & -5.407 & -5.152 & -5.213 & -5.510 & -5.152 & -4.897 & -4.958 & -5.422 & -5.065 & -4.810 & -4.871 & -5.524 & -5.167 & -4.912 & -4.973 \\
\hline 3 & -7.355 & -5.682 & -5.083 & -5.064 & -7.101 & -5.427 & -4.828 & -4.810 & -7.013 & -5.340 & -4.741 & -4.722 & -7.115 & -5.442 & -4.843 & -4.824 \\
\hline Delta & 4.836 & 1.133 & 0.321 & 0.297 & 4.836 & 1.133 & 0.321 & 0.297 & 4.836 & 1.133 & 0.321 & 0.297 & 4.836 & 1.133 & 0.321 & 0.297 \\
\hline Rank & 1 & 2 & 3 & 4 & 1 & 2 & 3 & 4 & 1 & 2 & 3 & 4 & 1 & 2 & 3 & 4 \\
\hline
\end{tabular}

Table A4. Average response table for signal-to-noise ratios for material removal rate (larger is better).

\begin{tabular}{|c|c|c|c|c|c|c|c|c|c|c|c|c|c|c|c|c|}
\hline \multicolumn{5}{|c|}{ Profile 1} & \multicolumn{4}{|c|}{ Profile 2} & \multicolumn{4}{|c|}{ Profile 3} & \multicolumn{4}{|c|}{ Profile 4} \\
\hline Level & $t$ & $V_{f}$ & $\mathbf{m}_{\mathbf{a}}$ & $P$ & $t$ & $V_{f}$ & $\mathbf{m}_{\mathbf{a}}$ & $P$ & $t$ & $V_{f}$ & $\mathbf{m}_{\mathrm{a}}$ & $P$ & $t$ & $V_{f}$ & $\mathrm{~m}_{\mathrm{a}}$ & $P$ \\
\hline 1 & 50.10 & 50.46 & 53.16 & 52.44 & 50.05 & 50.50 & 52.76 & 52.28 & 49.53 & 49.90 & 52.59 & 51.87 & 50.09 & 50.38 & 52.99 & 52.42 \\
\hline 2 & 53.87 & 53.64 & 53.22 & 53.04 & 53.66 & 53.36 & 53.02 & 52.66 & 53.30 & 53.07 & 52.66 & 52.47 & 53.77 & 53.53 & 53.18 & 52.95 \\
\hline 3 & 55.68 & 55.55 & 53.26 & 54.17 & 55.37 & 55.21 & 53.30 & 54.14 & 55.11 & 54.98 & 52.69 & 53.61 & 55.50 & 55.44 & 53.18 & 53.98 \\
\hline Delta & 5.58 & 5.08 & 0.10 & 1.74 & 5.32 & 4.71 & 0.54 & 1.86 & 5.58 & 5.08 & 0.10 & 1.74 & 5.41 & 5.06 & 0.20 & 1.55 \\
\hline Rank & 1 & 2 & 4 & 3 & 1 & 2 & 4 & 3 & 1 & 2 & 4 & 3 & 1 & 2 & 4 & 3 \\
\hline \multicolumn{5}{|c|}{ Profile 5} & \multicolumn{4}{|c|}{ Profile 6} & \multicolumn{4}{|c|}{ Profile 7} & \multicolumn{4}{|c|}{ Profile 8} \\
\hline Level & $t$ & $V_{f}$ & $\mathrm{~m}_{\mathrm{a}}$ & $P$ & $t$ & $V_{f}$ & $\mathrm{~m}_{\mathrm{a}}$ & $P$ & $t$ & $V_{f}$ & $\mathrm{~m}_{\mathrm{a}}$ & $P$ & $t$ & $V_{f}$ & $\mathrm{~m}_{\mathrm{a}}$ & $P$ \\
\hline 1 & 49.92 & 50.37 & 52.63 & 52.18 & 50.41 & 50.85 & 53.18 & 52.64 & 50.23 & 50.68 & 53.01 & 52.52 & 50.65 & 51.09 & 53.45 & 52.94 \\
\hline 2 & 53.53 & 53.23 & 52.89 & 52.56 & 53.96 & 53.67 & 53.28 & 53.12 & 53.79 & 53.49 & 53.11 & 53.00 & 54.20 & 53.91 & 53.53 & 53.42 \\
\hline 3 & 55.24 & 55.08 & 53.17 & 53.95 & 55.69 & 55.54 & 53.59 & 54.30 & 55.51 & 55.37 & 53.42 & 54.01 & 55.96 & 55.81 & 53.83 & 54.44 \\
\hline Delta & 5.32 & 4.71 & 0.54 & 1.77 & 5.28 & 4.69 & 0.41 & 1.67 & 5.28 & 4.69 & 0.41 & 1.49 & 5.30 & 4.72 & 0.38 & 1.50 \\
\hline Rank & 1 & 2 & 4 & 3 & 1 & 2 & 4 & 3 & 1 & 2 & 4 & 3 & 1 & 2 & 4 & 3 \\
\hline \multicolumn{5}{|c|}{ Profile 9} & \multicolumn{4}{|c|}{ Profile 10} & \multicolumn{4}{|c|}{ Profile 11} & \multicolumn{4}{|c|}{ Profile 12} \\
\hline Level & $t$ & $V_{f}$ & $\mathrm{~m}_{\mathrm{a}}$ & $P$ & $t$ & $V_{f}$ & $\mathrm{~m}_{\mathrm{a}}$ & $P$ & $t$ & $V_{f}$ & $\mathrm{~m}_{\mathrm{a}}$ & $P$ & $t$ & $V_{f}$ & $\mathrm{~m}_{\mathrm{a}}$ & $P$ \\
\hline 1 & 50.11 & 50.56 & 52.91 & 52.41 & 49.45 & 49.81 & 52.51 & 51.78 & 49.88 & 50.32 & 52.65 & 52.17 & 49.70 & 50.14 & 52.47 & 51.98 \\
\hline 2 & 53.67 & 53.37 & 52.99 & 52.89 & 53.22 & 52.98 & 52.57 & 52.38 & 53.43 & 53.13 & 52.75 & 52.65 & 53.25 & 52.95 & 52.57 & 52.46 \\
\hline 3 & 55.42 & 55.27 & 53.30 & 53.91 & 55.02 & 54.89 & 52.61 & 53.52 & 55.16 & 55.01 & 53.06 & 53.65 & 54.97 & 54.83 & 52.88 & 53.47 \\
\hline Delta & 5.30 & 4.72 & 0.38 & 1.50 & 5.58 & 5.08 & 0.10 & 1.74 & 5.28 & 4.69 & 0.41 & 1.49 & 5.28 & 4.69 & 0.41 & 1.49 \\
\hline Rank & 1 & 2 & 4 & 3 & 1 & 2 & 4 & 3 & 1 & 2 & 4 & 3 & 1 & 2 & 4 & 3 \\
\hline
\end{tabular}

\section{References}

1. Miao, X.; Wu, M.; Qiang, Z.; Wang, Q.; Miao, X. Study on optimization of a simulation method for abrasive water jet machining. Int. J. Adv. Manuf. Technol. 2017, 93, 587-593. [CrossRef]

2. Alsoufi, M.S. State-of-the-art in abrasive water jet cutting technology and the promise for micro-and nano-machining. Int. J. Mech. Eng. Appl. 2017, 5, 1. [CrossRef]

3. El-Domiaty, A.; Shabara, M.; Abdel-Rahman, A.; Al-Sabeeh, A. On the modelling of abrasive waterjet cutting. Int. J. Adv. Manuf. Technol. 1996, 12, 255-265. [CrossRef]

4. Radovanovic, M. Multi-Objective Optimization of Abrasive Water Jet Cutting Using MOGA. Procedia Manuf. 2020, 47, 781-787. [CrossRef]

5. Kechagias, J.; Petropoulos, G.; Vaxevanidis, N. Application of Taguchi design for quality characterization of abrasive water jet machining of TRIP sheet steels. Int. J. Adv. Manuf. Technol. 2012, 62, 635-643. [CrossRef] 
6. Veerappan, G.; Ravichandran, M. Experimental investigations on abrasive water jet machining of nickel-based superalloy. J. Braz. Soc. Mech. Sci. Eng. 2019, 41, 1-12. [CrossRef]

7. Begic-Hajdarevic, D.; Cekic, A.; Mehmedovic, M.; Djelmic, A. Experimental study on surface roughness in abrasive water jet cutting. Procedia Eng. 2015, 100, 394-399. [CrossRef]

8. Bhandarkar, V.; Singh, V.; Gupta, T. Experimental analysis and characterization of abrasive water jet machining of Inconel 718. Mater. Today Proc. 2020, 23, 647-650. [CrossRef]

9. Lehocka, D.; Botko, F.; Klich, J.; Sitek, L.; Hvizdos, P.; Fides, M.; Cep, R. Effect of pulsating water jet disintegration on hardness and elasticity modulus of austenitic stainless steel AISI 304L. Int. J. Adv. Manuf. Technol. 2020, 107, 1-12. [CrossRef]

10. Supriya, S.; Srinivas, S. Machinability studies on stainless steel by abrasive water jet-Review. Mater. Today Proc. 2018, 5, 2871-2876. [CrossRef]

11. Desu, R.K.; Krishnamurthy, H.N.; Balu, A.; Gupta, A.K.; Singh, S.K. Mechanical properties of Austenitic Stainless Steel 304L and 316L at elevated temperatures. J. Mater. Res. Technol. 2016, 5, 13-20. [CrossRef]

12. Barabas, S.A.; Florescu, A. Optimization Method of Abrasive Water Jet Cutting of Welded Overlay Materials. Metals 2019, 9, 1046. [CrossRef]

13. Kuntoğlu, M.; Acar, O.; Gupta, M.K.; Sağlam, H.; Sarikaya, M.; Giasin, K.; Pimenov, D.Y. Parametric Optimization for Cutting Forces and Material Removal Rate in the Turning of AISI 5140. Machines 2021, 9, 90. [CrossRef]

14. Kuntoğlu, M.; Aslan, A.; Pimenov, D.Y.; Giasin, K.; Mikolajczyk, T.; Sharma, S. Modeling of cutting parameters and tool geometry for multi-criteria optimization of surface roughness and vibration via response surface methodology in turning of AISI 5140 steel. Materials 2020, 13, 4242. [CrossRef]

15. Natarajan, Y.; Murugesan, P.K.; Mohan, M.; Khan, S.A.L.A. Abrasive Water Jet Machining process: A state of art of review. J. Manuf. Process. 2020, 49, 271-322. [CrossRef]

16. Aamir, M.; Giasin, K.; Tolouei-Rad, M.; Vafadar, A. A review: Drilling performance and hole quality of aluminium alloys for aerospace applications. J. Mater. Res. Technol. 2020, 9, 12484-12500. [CrossRef]

17. Sutowska, M.; Kapłonek, W.; Pimenov, D.Y.; Gupta, M.K.; Mia, M.; Sharma, S. Influence of variable radius of cutting head trajectory on quality of cutting kerf in the abrasive water jet process for soda-lime glass. Materials 2020, 13, 4277. [CrossRef]

18. Liu, X.; Liang, Z.; Wen, G.; Yuan, X. Waterjet machining and research developments: A review. Int. J. Adv. Manuf. Technol. 2019, 102, 1257-1335. [CrossRef]

19. Singh, D.; Chaturvedi, V. Investigation of optimal processing condition for abrasive water jet machining for stainless steel AISI 304 using grey relational analysis coupled with S/N ratio. Appl. Mech. Mater. 2014, 592-594, 438-443. [CrossRef]

20. Löschner, P.; Jarosz, K.; Niesłony, P. Investigation of the effect of cutting speed on surface quality in abrasive water jet cutting of 316L stainless steel. Procedia Eng. 2016, 149, 276-282. [CrossRef]

21. Karthik, K.; Sundarsingh, D.S.; Harivignesh, M.; Karthick, R.G.; Praveen, M. Optimization of machining parameters in abrasive water jet cutting of stainless steel 304. Mater. Today Proc. 2021, 46, 1384-1389. [CrossRef]

22. Kmec, J.; Gombár, M.; Harničárová, M.; Valíček, J.; Kušnerová, M.; Kř́ǔz, J.; Kadnár, M.; Karková, M.; Vagaská, A. The Predictive Model of Surface Texture Generated by Abrasive Water Jet for Austenitic Steels. Appl. Sci. 2020, 10, 3159. [CrossRef]

23. Hlaváč, L.M.; Hlaváčová, I.M.; Geryk, V.; Plančár, Š. Investigation of the taper of kerfs cut in steels by AWJ. Int. J. Adv. Manuf. Technol. 2015, 77, 1811-1818. [CrossRef]

24. Aamir, M.; Tu, S.; Tolouei-Rad, M.; Giasin, K.; Vafadar, A. Optimization and modeling of process parameters in multi-hole simultaneous drilling using taguchi method and fuzzy logic approach. Materials 2020, 13, 680. [CrossRef] [PubMed]

25. Lin, C. Use of the Taguchi method and grey relational analysis to optimize turning operations with multiple performance characteristics. Mater. Manuf. Process. 2004, 19, 209-220. [CrossRef]

26. Maneiah, D.; Shunmugasundaram, M.; Reddy, A.R.; Begum, Z. Optimization of machining parameters for surface roughness during abrasive water jet machining of aluminium/magnesium hybrid metal matrix composites. Mater. Today Proc. 2020, 27, 1293-1298. [CrossRef]

27. Sharma, M.K.; Chaudhary, H.; Kumar, A. Optimization of abrasive waterjet machining process parameters on aluminium AL-6061. Int. J. Sci. Res. 2017, 6, 869-874.

28. Otto, K.N.; Antonsson, E.K. Extensions to the Taguchi method of product design. J. Mech. Des. 1993, 115, 5-13. [CrossRef]

29. Jiang, W.; Cao, Y.; Jiang, Y.; Liu, Y.; Mao, Q.; Zhou, H.; Liao, X.; Zhao, Y. Effects of nanostructural hierarchy on the hardness and thermal stability of an austenitic stainless steel. J. Mater. Res. Technol. 2021, 12, 376-384. [CrossRef]

30. Kaladhar, M.; Subbaiah, K.V.; Rao, C.S. Machining of austenitic stainless steels-A review. Int. J. Mach. Mach. Mater. 2012, 12, 178-192. [CrossRef]

31. Ramana, M.V.; Kumar, B.R.; Krishna, M.; Rao, M.V.; Kumar, V. Optimization and influence of process parameters of dissimilar SS304L-SS430 joints produced by Robotic TIG welding. Mater. Today Proc. 2020, 23, 479-482. [CrossRef]

32. Llanto, J.M.; Tolouei-Rad, M.; Vafadar, A.; Aamir, M. Impacts of Traverse Speed and Material Thickness on Abrasive Waterjet Contour Cutting of Austenitic Stainless Steel AISI 304L. Appl. Sci. 2021, 11, 4925. [CrossRef]

33. Wang, S.; Zhang, S.; Wu, Y.; Yang, F. A key parameter to characterize the kerf profile error generated by abrasive water-jet. Int. J. Adv. Manuf. Technol. 2017, 90, 1265-1275. [CrossRef]

34. Pawar, P.J.; Vidhate, U.S.; Khalkar, M.Y. Improving the quality characteristics of abrasive water jet machining of marble material using multi-objective artificial bee colony algorithm. J. Comput. Des. Eng. 2018, 5, 319-328. [CrossRef] 
35. Hlavac, L.M.; Hlavacova, I.M.; Arleo, F.; Vigano, F.; Annoni, M.P.G.; Geryk, V. Shape distortion reduction method for abrasive water jet (AWJ) cutting. Precis. Eng. 2018, 53, 194-202. [CrossRef]

36. Kumar, R.; Chattopadhyaya, S.; Dixit, A.R.; Bora, B.; Zelenak, M.; Foldyna, J.; Hloch, S.; Hlavacek, P.; Scucka, J.; Klich, J. Surface integrity analysis of abrasive water jet-cut surfaces of friction stir welded joints. Int. J. Adv. Manuf. Technol. 2017, 88, 1687-1701. [CrossRef]

37. Uthayakumar, M.; Khan, M.A.; Kumaran, S.T.; Slota, A.; Zajac, J. Machinability of nickel-based superalloy by abrasive water jet machining. Mater. Manuf. Process. 2016, 31, 1733-1739. [CrossRef]

38. Rao, R.V.; Rai, D.P.; Balic, J. Multi-objective optimization of abrasive waterjet machining process using Jaya algorithm and PROMETHEE Method. J. Intell. Manuf. 2019, 30, 2101-2127. [CrossRef]

39. Khan, M.A.; Gupta, K. Machinability Studies on Abrasive Water Jet Machining of Low Alloy Steel for Different Thickness. IOP Conf. Ser. Mater. Sci. Eng. 2020, 709, 044099. [CrossRef]

40. Llanto, J.M.; Tolouei-Rad, M.; Vafadar, A.; Aamir, M. Recent Progress Trend on Abrasive Waterjet Cutting of Metallic Materials: A Review. Appl. Sci. 2021, 11, 3344. [CrossRef]

41. Gnanavelbabu, A.; Saravanan, P.; Rajkumar, K.; Karthikeyan, S. Experimental investigations on multiple responses in abrasive waterjet machining of Ti-6Al-4V alloy. Mater. Today Proc. 2018, 5, 13413-13421. [CrossRef]

42. Barad, M. Taguchi Experimental-Design Techniques-Revisited. In Transformation of Science and Technology into Productive Power, Supplement; Taylor \& Francis Ltd.: Oxfordshire, UK, 1991; pp. 1101-1104.

43. Patel Gowdru Chandrashekarappa, M.; Kumar, S.; Pimenov, D.Y.; Giasin, K. Experimental Analysis and Optimization of EDM Parameters on HcHcr Steel in Context with Different Electrodes and Dielectric Fluids Using Hybrid Taguchi-Based PCA-Utility and CRITIC-Utility Approaches. Metals 2021, 11, 419. [CrossRef]

44. Aamir, M.; Tolouei-Rad, M.; Giasin, K.; Vafadar, A. Machinability of Al2024, Al6061, and Al5083 alloys using multi-hole simultaneous drilling approach. J. Mater. Res. Technol. 2020, 9, 10991-11002. [CrossRef]

45. Aamir, M.; Giasin, K.; Tolouei-Rad, M.; Ud Din, I.; Hanif, M.I.; Kuklu, U.; Pimenov, D.Y.; Ikhlaq, M. Effect of Cutting Parameters and Tool Geometry on the Performance Analysis of One-Shot Drilling Process of AA2024-T3. Metals 2021, 11, 854. [CrossRef]

46. Aamir, M.; Tolouei-Rad, M.; Giasin, K.; Vafadar, A. Feasibility of tool configuration and the effect of tool material, and tool geometry in multi-hole simultaneous drilling of Al2024. Int. J. Adv. Manuf. Technol. 2020, 111, 861-879. [CrossRef]

47. Sasikumar, K.; Arulshri, K.; Ponappa, K.; Uthayakumar, M. A study on kerf characteristics of hybrid aluminium 7075 metal matrix composites machined using abrasive water jet machining technology. Proc. Inst. Mech. Eng. Part B J. Eng. Manuf. 2018, 232, 690-704. [CrossRef]

48. Yu, Y.; Sun, T.; Yuan, Y.; Gao, H.; Wang, X. Experimental investigation into the effect of abrasive process parameters on the cutting performance for abrasive waterjet technology: A case study. Int. J. Adv. Manuf. Technol. 2020, 107, 2757-2765. [CrossRef]

49. Selvan, M.C.P.; Raju, N.M.S.; Sachidananda, H. Effects of process parameters on surface roughness in abrasive waterjet cutting of aluminium. Front. Mech. Eng. 2012, 7, 439-444. [CrossRef]

50. Thamizhvalavan, P.; Arivazhagan, S.; Yuvaraj, N.; Ramesh, B. Machinability study of abrasive aqua jet parameters on hybrid metal matrix composite. Mater. Manuf. Process. 2019, 34, 321-344. [CrossRef]

51. Ishfaq, K.; Ahmad Mufti, N.; Ahmed, N.; Pervaiz, S. Abrasive waterjet cutting of cladded material: Kerf taper and MRR analysis. Mater. Manuf. Process. 2019, 34, 544-553. [CrossRef]

52. Hashish, M. Optimization Factors in Abrasive-Waterjet Machining. J. Eng. Ind. ASME 1991, 113, 29-37. [CrossRef]

53. Liu, S.; Zhou, F.; Li, H.; Chen, Y.; Wang, F.; Guo, C. Experimental Investigation of Hard Rock Breaking Using a Conical Pick Assisted by Abrasive Water Jet. Rock Mech. Rock Eng. 2020, 59, 1-10. [CrossRef] 